Article

\title{
Thermally Reversible Polymeric Networks from Vegetable Oils
}

\author{
Frita Yuliati ${ }^{1,2}$, Jennifer Hong ${ }^{2}$, Keshia S. Indriadi ${ }^{2}$, Francesco Picchioni ${ }^{2} \mathbb{D}$ and \\ Ranjita K. Bose $2, * \mathbb{D}$ \\ 1 Laboratory for Polymer Technology, Agency for the Assessment and Application of Technology, Jalan M.H. \\ Thamrin no. 8, Jakarta 10340, Indonesia; frita.yuliati@bppt.go.id \\ 2 Department of Chemical Engineering, University of Groningen, Nijenborgh 4, \\ 9747 AG Groningen, The Netherlands; jennifer.hong905@gmail.com (J.H.); \\ keshia.saradima@gmail.com (K.S.I.); f.picchioni@rug.nl (F.P.) \\ * Correspondence: r.k.bose@rug.nl; Tel.: +31-503-634-486
}

Received: 26 June 2020; Accepted: 25 July 2020; Published: 30 July 2020

check for updates

\begin{abstract}
Low cross-link density thermally reversible networks were successfully synthesized from jatropha and sunflower oils. The oils were epoxidized and subsequently reacted with furfurylamine to attach furan groups onto the triglycerides, preferably at the epoxide sites rather than at the ester ones. Under the same reaction conditions, the modified jatropha oil retained the triglyceride structure more efficiently than its sunflower-based counterpart, i.e., the ester aminolysis reaction was less relevant for the jatropha oil. These furan-modified oils were then reacted with mixtures of aliphatic and aromatic bismaleimides, viz. 1,12-bismaleimido dodecane and 1,1'-(methylenedi-4,1-phenylene)bismaleimide, resulting in a series of polymers with $\mathrm{T}_{\mathrm{g}}$ ranging between 3.6 and $19.8^{\circ} \mathrm{C}$. Changes in the chemical structure and mechanical properties during recurrent thermal cycles suggested that the Diels-Alder and retro-Diels-Alder reactions occurred. However, the reversibility was reduced over the thermal cycles due to several possible causes. There are indications that the maleimide groups were homopolymerized and the Diels-Alder adducts were aromatized, leading to irreversibly cross-linked polymers. Two of the polymers were successfully applied as adhesives without modifications. This result demonstrates one of the potential applications of these polymers.
\end{abstract}

Keywords: jatropha oil; sunflower oil; Diels-Alder; thermally reversible networks

\section{Introduction}

Increasing concerns about the unstable prices of petroleum resources along with the questions regarding its availability in the future have initiated a growing interest in the use of renewable resources [1-3]. Various vegetable oils are produced on a large scale worldwide. Most of these oils are consumed as food and feed, and to a lesser extent used as raw materials for fuels and chemicals, including a wide application in the polymer industry $[4,5]$.

Vegetable oils are extensively utilized in different polymeric materials such as the classic use as oil paint medium (drying oil) [6-9] to the production of contemporary materials as polyesters [10,11] and polyurethanes [12,13]. Numerous researches have employed different chemical reactions to synthesize various polymers from the oils, among others, cationic polymerization [14], metathesis [15,16], thiol-ene [17], and thiol-yne [18], Michael addition [19], ATRP [20], and Diels-Alder (DA) reactions [2,21-24]. The DA reaction is a very interesting option for polymerization because it can be reversed at an elevated temperature. Applying this reaction to cross-linked polymers offers the possibility of reprocessing the material, which is not an option with the conventional ones [25]. 
These reprocessable materials possess distinctive capabilities of self-healing and recyclability, making them advantageous in practical, economical, and environmental aspects.

The DA reaction occurs between a conjugated diene with a dienophile to form a six-membered hydroaromatic or heteroaromatic ring, with the formation of two $\sigma$ bonds at the expense of two $\pi$ bonds of the precursors [26]. Application of this reaction on vegetable oils and their derivatives is not new and was intended for various applications. Some vegetable oil structures include dienes which can be modified into conjugated ones. Safflower oil was isomerized to arrange the C-C double bonds into conjugated configuration and used in DA reactions, in earlier works dating back to 1971 and 1972 [27-29]. Esters of the modified oil were successfully reacted with maleic anhydride, styrene, and acrylic acid as dienophiles [27-29]. Another interesting raw material is tung oil, which naturally contains conjugated trienes. This oil was reacted with maleic anhydride at $150{ }^{\circ} \mathrm{C}$ for $2 \mathrm{~h}$, producing a high yield of DA product [30]. Another research group reported the polymerization of the same oil with 1,1'-(methylenedi-4,1-phenylene)bismaleimide with varied compositions, producing polymers with $\mathrm{T}_{\mathrm{g}}$ varying from $111-150^{\circ} \mathrm{C}$ and tensile modulus in the range of 1.67 to $2.58 \mathrm{GPa}$ [31]. However, another work found that similar polymers synthesized from tung oil and different bismaleimides did not demonstrate the occurrence of retro-Diels-Alder (rDA) reaction, and thus could not be reprocessed under heating [23]. This might at least suggest the presence of side reactions besides rDA at relatively high temperatures.

Other synthetic routes were developed in utilizing different vegetable oils for DA reaction-based polymers. A popular way of doing so is by appending groups containing dienes and dienophiles to vegetable oil derivatives and subsequently combining them in a DA reaction into linear or cross-linked polymers. An example to this route is the modification of 10-undecenoic acid and undecenoic alcohol into monomers bearing two furans or a furan and a protected maleimide. The first monomer was reacted with 1,6-bismaleimidohexane while the second was reacted by itself after removing the protecting group. The reaction in solution took place over several days to obtain high conversions with the reversed reaction consumed similar amount of time [32], and this expected to proceed faster when using higher concentrations [21]. Multifuranic structures can also be built from undecenoic alcohol by combining three molecules of the alcohol into a triglyceride and attaching furans to the terminal alkenes. The trifuranic monomer was cross-linked with bismaleimide in a reaction monitored by NMR. It was found that high yield was obtained and the reversibility feature occurred in the system [2].

Most vegetable oils do not possess conjugated dienes or terminal alkenes. Attaching furans into the oil structure can be performed by first modifying the unsaturations to make it more reactive, for example, by epoxidation. Epoxidized oils can further be modified to yield acrylated vegetable oils such as the commercially available acrylated epoxidized soybean oil (AESO). In a study, furans were successfully attached to AESO via Michael addition, leading to triglycerides comprising three furan moieties. The furan-functionalized molecule was reacted with bismaleimide to obtain a cross-linked polymer. This polymer underwent rDA reaction at temperatures ranging between 103 and $134{ }^{\circ} \mathrm{C}$ [33].

Other studies attempted to use a shorter route, attaching furans directly to epoxidized oils by reacting them with furfurylamine. The amine group also reacted with esters, resulting in linear structures comprising one or two furan moieties instead of triglycerides with at least three furans. After reactions with bismaleimides, brittle polymers were obtained as the products [24,34]. In our previous work [35], the conditions for a similar functionalization of jatropha oil were optimized, attaining high epoxide conversion while retaining a majority of esters. When the product was cross-linked with bismaleimides, tougher polymers can be expected as a result of longer hydrocarbon chains functioning as the "backbone" of the polymers with relatively lower cross-link density.

In this work, we cross-linked the furan-functionalized jatropha oil with combinations of two different bismaleimides in order to obtain polymers with different rigidities (Figure 1). The first is a commercially available bismaleimide comprising two aromatic rings and the second has an aliphatic chain instead of the rings. The same procedure was applied to sunflower oil to understand to extent a different level of functionalization influences the properties of the resultant polymers. The occurrence 
of DA and r-DA reactions was also investigated by observing changes in chemical structure and mechanical properties throughout thermal treatments.

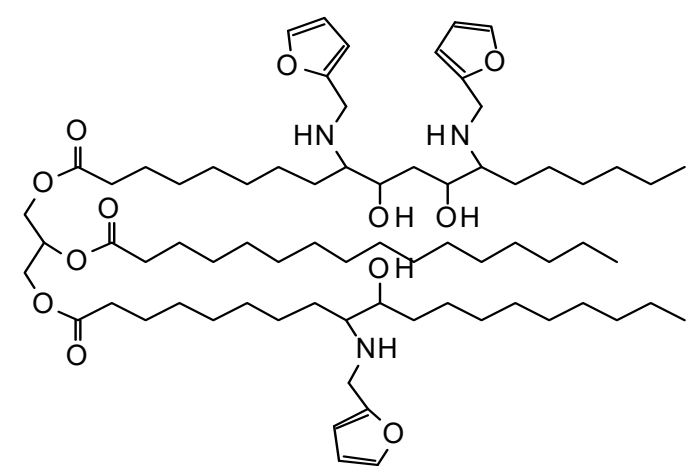

Furan-functionalized jatropha oil<smiles>O=C1C=CC(O)N1C1C=CC(CC2C=CC(N3C(O)C=CC3O)CC2)CC1</smiles>

Aromatic Bismaleimide<smiles>O=C1C=CC(=O)N1CCCCCCCCCCCN1C(=O)C=CC1=O</smiles>

Figure 1. Synthesis of a thermally reversible polymer by reacting furan-functionalized jatropha oil with a mixture of bismaleimides.

\section{Materials and Methods}

\subsection{Materials}

Jatropha curcas oil (JO) was purchased from Dilligent BV, Eersel, Netherlands. Sunflower oil was purchased from Jumbo supermarket. Hydrogen peroxide solution $(30 \%)$, formic acid ( $\geq 98 \%)$, sodium chloride ( $\geq 99 \%)$, furfurylamine $(\geq 99 \%), 1,12$-diaminododecane $(98 \%)$, tris(2-aminoethyl)amine $(96 \%)$, maleic anhydride $(99 \%)$, triethylamine $(\geq 99.5 \%)$, acetic anhydride ( $\geq 99 \%)$, DMF anhydrous (99.8\%), silica gel 60 A 230-400\#, silica gel technical grade 40 6-12\#, 1,1'-(methylenedi-4,1-phenylene)bismaleimide (95\%), and 2,5-dimethylfuran 99\% were obtained from Sigma Aldrich (Munich, Germany). Peroxide test strips $\left(0.5,2,5,10,25 \mathrm{mg} / \mathrm{L} \mathrm{H}_{2} \mathrm{O}_{2}\right.$ ) were procured from Merck (Darmstadt, Germany). Toluene (99.5\%) and dichloromethane (99.5\%) were purchased from Macron Fine Chemicals (Deventer, The Netherlands), whereas sodium chloride $(\geq 99 \%)$ and lithium bromide ( $\geq 98 \%$ ) were obtained from Fluka (Landsmeer, The Netherlands). A representative all-purpose mounting glue was purchased from Bison (Rotterdam, The Netherlands), while aluminum sheets $\left(20 \times 20 \times 0.01 \mathrm{~cm}^{3}\right)$ were purchased from aluminiumfolie.nl (Gorinchem, The Netherlands).

\subsection{Methods}

\subsubsection{Epoxidation of Jatropha and Sunflower Oils}

Epoxidation of the vegetable oils was performed according to a previous work [24] with some modification. Here, $20 \mathrm{~mL}(0.02 \mathrm{~mol})$ of the oil was dissolved in $100 \mathrm{~mL}$ of toluene and heated to $70{ }^{\circ} \mathrm{C}$. Into the solution, formic acid and $30 \% \mathrm{H}_{2} \mathrm{O}_{2}$ solution $(12 \mathrm{~mL}, 0.53 \mathrm{~mol}$, and $150 \mathrm{~mL}, 1.47 \mathrm{~mol}$, respectively) were added dropwise in one hour while being stirred, and the stirring was continued 
for $24 \mathrm{~h}$. The mixture was separated by using a separating funnel. The organic phase was collected and excess hydrogen peroxide was removed by liquid-liquid extraction by using $150 \mathrm{~mL}$ of $5 \% \mathrm{NaCl}$ solution. The concentration of the remaining hydrogen peroxide was tested by using peroxide test strips. Toluene was evaporated by using a rotary evaporator, and the remaining water was absorbed by using 6-12 \# silica gel.

\subsubsection{Furan-functionalization of the Epoxidized Oils}

Furan-derivatization of epoxidized oils was performed based on a reported method [35]. $5 \mathrm{~g}$ $(0.005 \mathrm{~mol})$ of purified epoxidized oil and furfurylamine were reacted with the molar ratio between the epoxides and furfurylamine of 1:1. Lithium bromide was introduced at the amount of $100 \mathrm{~mol} \%$ of the triglyceride. The mixture was stirred at $400 \mathrm{rpm}$, at the temperature of $115^{\circ} \mathrm{C}$ for $24 \mathrm{~h}$. The products were dissolved in chloroform, then the unreacted furfurylamine was washed with $250 \mathrm{~mL}$ of MiliQ water. The water and organic phase were separated by using a separating funnel, and the organic phase was used in the polymerization afterwards.

\subsubsection{Synthesis of 1,12-Bismaleimido Dodecane}

The 1,12-bismaleimido dodecane was synthesized according to a reported procedure [36,37]. $7.3 \mathrm{~g}(0.075 \mathrm{~mol})$ of maleic anhydride was dissolved in $20 \mathrm{~mL}$ of dimethylformamide and heated to $80^{\circ} \mathrm{C} .5 .0 \mathrm{~g}(0.025 \mathrm{~mol})$ of 1,12-diaminododecane was added into the solution and stirred for $1 \mathrm{~h}$ until a clear solution was formed. Acetic anhydride $(15.3 \mathrm{~g}, 0.15 \mathrm{~mol})$, triethylamine $(1.0 \mathrm{~g}, 0.0099 \mathrm{~mol})$, and nickel(II)acetate $(0.10 \mathrm{~g}, 0.00057 \mathrm{~mol})$ were added into the solution. The stirring was continued for $30 \mathrm{~min}$. Then, $20 \mathrm{~mL}$ of mili-Q water was added into the solution, and the solvent was removed by using a rotary evaporator. The residue was dissolved in $200 \mathrm{~mL}$ of dichloromethane and shaken with $30 \mathrm{~g}$ of silica gel for $5 \mathrm{~min}$. Silica gel was removed by filtration, after which chloroform was removed by vacuum evaporation. The residue was dissolved in $50 \mathrm{~mL}$ of boiling ethanol, before the solution was kept at $0{ }^{\circ} \mathrm{C}$ overnight. Crystals were formed and retrieved by filtration.

\subsubsection{Model Reactions}

Model reactions between furan and maleimide groups were performed by using dimethylfuran and each of the aromatic and aliphatic bismaleimide. $0.8 \mathrm{~g}(0.008 \mathrm{~mol})$ of dimethylfuran was mixed with $0.1 \mathrm{~g}(0.0003 \mathrm{~mol})$ of the aromatic bismaleimide or $0.1 \mathrm{~g}(0.0003 \mathrm{~mol})$ of the aliphatic bismaleimide. The mixtures were stirred by using a magnetic stirrer at $400 \mathrm{rpm}, 50{ }^{\circ} \mathrm{C}$, for $24 \mathrm{~h}$. The occurrence of DA and $\mathrm{rDA}$ reactions was observed by FTIR identification during two heating-cooling cycles between $50-110{ }^{\circ} \mathrm{C}$.

\subsubsection{Cross-Linking via the Diels-Alder Reaction}

A mixture of aromatic and aliphatic bismaleimide (with compositions according to Table 1) was added to a $10 \%$ solution of furan-functionalized vegetable oil in chloroform, with the molar ratio of furans and maleimides of 1:1. This mixture was stirred at $400 \mathrm{rpm}$ at $50{ }^{\circ} \mathrm{C}$ for $24 \mathrm{~h}$. Chloroform was then removed from the solution via evaporation. The products were kept in a vacuum oven at $50{ }^{\circ} \mathrm{C}$ for $24 \mathrm{~h}$ to remove the remaining solvent and further cure the polymers. The curing process was continued at room temperature for two weeks.

\subsubsection{Characterization}

The compositions of vegetable oils, epoxidized oils, and furan-functionalized oils were analyzed by using ${ }^{1} \mathrm{H}-\mathrm{NMR}$ in a Varian Oxford $300 \mathrm{MHz}$ NMR (Agilent, Santa Clara, CA, USA) with deuterated chloroform as a solvent. The occurrence of the DA and $\mathrm{rDA}$ reactions in the products of the model reaction as well as the polymers were identified by using an attenuated total reflectance (ATR) crystal, in an IRT Racer-100 Shimadzu FTIR (Kyoto, Japan), equipped with Specac Golden Gate ATR Top and 
West 6100+ temperature controller (Philadelphia, PA, USA). Spectra were recorded in the absorbance mode between 500 and $4000 \mathrm{~cm}^{-1}$, with 64 repetitions and a resolution of $8 \mathrm{~cm}^{-1}$. The measurement was performed every $20^{\circ} \mathrm{C}$ during two heating-cooling cycles. For the model compound, the preferred temperature range was between $50^{\circ} \mathrm{C}$ and $110^{\circ} \mathrm{C}$, while for the polymer it was between $50{ }^{\circ} \mathrm{C}$ and $150{ }^{\circ} \mathrm{C}$. The signals assigned to the DA adducts and maleimides were deconvoluted and the areas were calculated by using Origin 8.1 software (Northampton, MA, USA). The spectra of the model compounds were normalized to the $\mathrm{C}=\mathrm{O}$ signal of the maleimides at $1700 \mathrm{~cm}^{-1}$, while those of the polymers to the unreacted alkyl signal at $2845 \mathrm{~cm}^{-1}$.

Table 1. Composition of bismaleimides in different polymers.

\begin{tabular}{cccc}
\hline Sample Codes & Vegetable Oil & Aliphatic Bismaleimide & Aromatic Bismaleimide \\
\hline J-40-60 & Jatropha & $40 \%$ & $60 \%$ \\
J-60-40 & Jatropha & $60 \%$ & $40 \%$ \\
J-80-20 & Jatropha & $80 \%$ & $20 \%$ \\
SF-60-40 & Sunflower & $60 \%$ & $40 \%$ \\
SF- $80-20$ & Sunflower & $80 \%$ & $20 \%$ \\
SF-100-0 & Sunflower & $100 \%$ & 0 \\
\hline
\end{tabular}

The thermo-mechanical properties of the polymers were measured by using a Perkin Elmer DMA 8000 (Waltham, MA, USA), using the single cantilever mode. The measurements were performed in a temperature sweep experiments between 5 and $55^{\circ} \mathrm{C}$. Furthermore, the DA and rDA reactions were observed by measuring the polymers in three heating and cooling cycles between 0 and $150{ }^{\circ} \mathrm{C}$. For these experiments, the polymer samples were held in between thin pockets made of stainless steel. Due to the use of these material pockets the absolute values of the modulus obtained include the contribution from the polymer samples as well as the outer stainless-steel pocket. The samples were loaded at room temperature, then the temperature was increased to $150^{\circ} \mathrm{C}$ and cooled to $0^{\circ} \mathrm{C}$. All DMA measurements were performed with $0.005 \mathrm{~mm}$ amplitude, at $1 \mathrm{~Hz}$ frequency. The samples used in the DMA measurement were collected in $4 \mathrm{~mL}$ vials and subjected to a gel content measurement according to a reported method [38] with some modification. THF was added to these vials at 20 times the mass of the samples. The vials were closed with the lids and let sit at room temperature for $24 \mathrm{~h}$, after which the mixtures were filtered. The retained solid was dried and weighed by using an analytical balance. The amount of insoluble polymer was calculated by using Equation (1).

$$
\% \text { Insoluble }=\frac{m_{0}-m_{1}}{m_{0}} \times 100 \%
$$

\subsubsection{Polymer Performance as Adhesive Test}

The polymers J-40-60 and SF-80-20 were applied to adhere two aluminum sheets. The adhesive performance was measured according to ASTM method D1876-08 [39] with some modifications. $3 \mathrm{~g}$ of the polymer was shaped into sheets by compression molding at $70{ }^{\circ} \mathrm{C}$ for $5 \mathrm{~min}$, at a pressure of $25 \mathrm{kN}$. A polymer sheet $\left(15 \times 20 \mathrm{~cm}^{2}\right.$, instead of $15.2 \times 24.1 \mathrm{~cm}^{2}$ according to the ASTM method) was placed between the two aluminum sheets $\left(20 \times 20 \mathrm{~cm}^{2}\right.$, instead of $15.2 \times 30.5 \mathrm{~cm}^{2}$ stated in the testing standard). The sandwich was compressed at $70{ }^{\circ} \mathrm{C}$ for $5 \mathrm{~min}$ at a pressure of $25 \mathrm{kN}$. The adhesive was allowed to cure at room temperature for 2 days. The sheets were cut into stripes $\left(2 \times 20 \mathrm{~cm}^{2}\right.$, as opposed to $2.5 \times 30.5 \mathrm{~cm}^{2}$ stated in the testing standard). Nine specimens were tested for each adhesive formulation. The peel resistance of the adhesive was measured by a universal test device shown in Figure 2. The speed of the machine was set at $254 \mathrm{~mm} / \mathrm{min}$. The data collected was load versus position. The peel resistance was calculated as the average load $(\mathrm{kg})$ divided by the stripe width (cm). Due to slight deviations of the testing protocol with respect to the ASTM standard (vide supra), a commercial all-purpose mounting glue was tested as a comparison in order to correctly benchmark our results. The adhesive was applied to the aluminum sheets by using a scraper. A uniform load was 
applied to the adhered sheets for 2 days. The sandwich was prepared for a peel test using the same method as used for the samples prepared in this study.

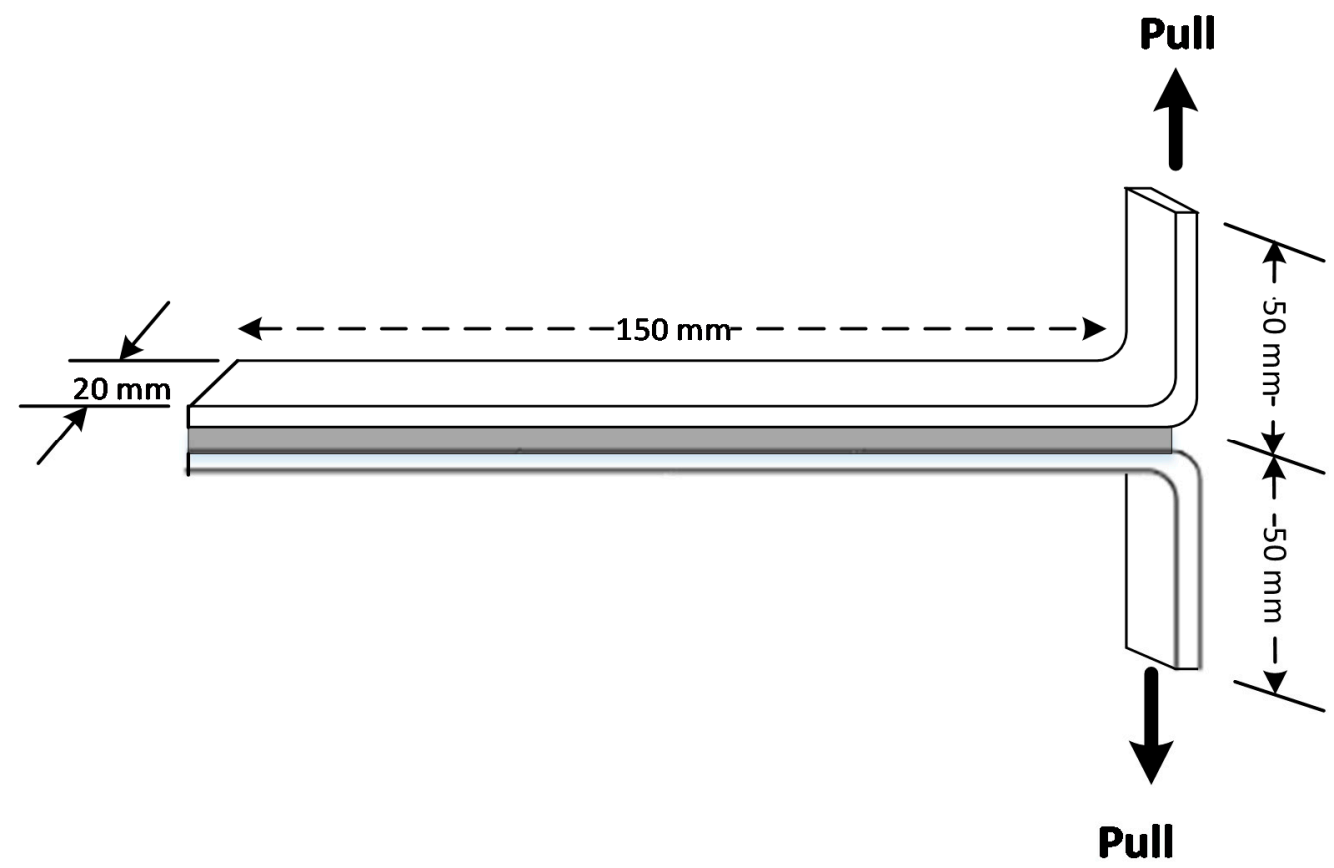

Figure 2. T-peel testing scheme according to ASTM D 1876-08 with some modifications.

\section{Results and Discussion}

\subsection{Epoxidation of the Vegetable Oils}

The first step in this work is epoxidation of the vegetable oils according to a previous work [40], which entails the use of an excessive $\mathrm{H}_{2} \mathrm{O}_{2}$ to ensure a complete conversion of the $\mathrm{C}-\mathrm{C}$ double bonds. The vegetable oils were analyzed by using ${ }^{1} \mathrm{H}$ NMR, before and after epoxidation (Figure 3 ). Jatropha and sunflower oils have similar structures with a different number of unsaturations. Therefore, their NMR spectra are similar, only differing in the intensity of signals related to vinylic and allylic protons. Full unsaturation conversion was recognized by the disappearance of signals related to the double bonds. The signal of the vinylic proton at $5.34 \mathrm{ppm}$ is slightly overlapping with a signal representing a proton on the glyceride group. Therefore, other signals related to allylic protons $(2.01 \mathrm{ppm})$ and bisallylic ones $(2.75 \mathrm{ppm})$ were used in determining the progress of the reaction. The average number of epoxide rings in a triglyceride molecule was determined by the area below the epoxide signals (2.82-3.18 ppm), with terminal methyl signals $(0.88 \mathrm{ppm})$ used as an internal standard. It was found that the epoxidized jatropha and sunflower oils contained on average 3.27 and 4.36 epoxides in each triglyceride molecules. As displayed in Figure 3, the structure of epoxidized jatropha and sunflower oils are similar. However, the epoxidized sunflower oil spectrum contains stronger epoxide signal than jatropha, due to a higher number of epoxides in each triglyceride.

\subsection{Furan-Functionalization of the Epoxidized Oil}

The epoxidized oils were reacted with furfurylamine in order to attach furans to the epoxide sites via a ring opening reaction. The amines also reacted with the esters, thus an unwanted ester aminolysis reaction also occurred. In a previous work [35], the reaction was optimized with epoxidized jatropha oil as a reactant. The optimum condition was found to be at $115^{\circ} \mathrm{C}$ for $24 \mathrm{~h}$, with a $1: 1$ molar ratio of epoxides to furfurylamine and $100 \%$ mol of $\mathrm{LiBr}$ loading, according to which the unwanted side reactions were minimized. Full epoxide conversion was difficult to achieve probably because of the presence, in some of the fatty acid chains, of two neighboring epoxide groups, with one of 
them being therefore sterically hindered [21]. According to NMR spectra of the products (Figure 4), furan-functionalized jatropha oil used in this work had on average 2.36 and 0.73 units of esters and epoxides remaining, with an average of 2.57 furans attached to each triglyceride molecule. When the same reaction condition was applied to the epoxidized sunflower oil, it was found that the epoxide conversion was lower and the ester conversion was higher. The sunflower-based product had on average 2.00 and 1.27 units of esters and epoxides remained, with 3.42 furans attached to each triglyceride. These results suggest that the products contain a mixture of mono-, di-, and triglycerides and fatty chains containing furans in their structures. The jatropha-based product contained a larger portion of triglycerides than the sunflower-based product. This distribution in chain length and functionalization of the precursor stems from and dovetails the original structure of the vegetable oil. Nevertheless, it must be noted here that the functionalization degree is in all cases high enough $(>2)$ to ensure the formation of a polymeric network after curing.

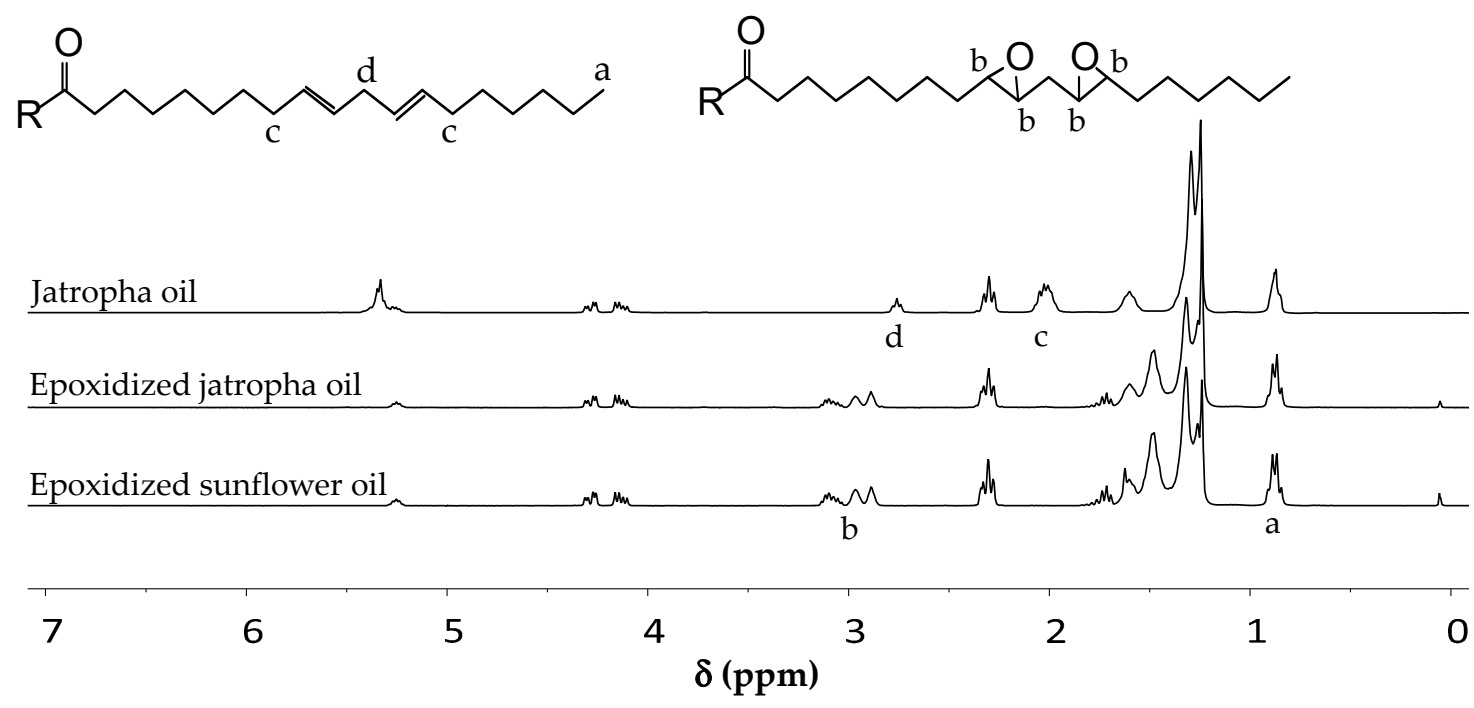

Figure 3. Proton NMR spectra of epoxidized jatropha and sunflower oils compared to jatropha oil.

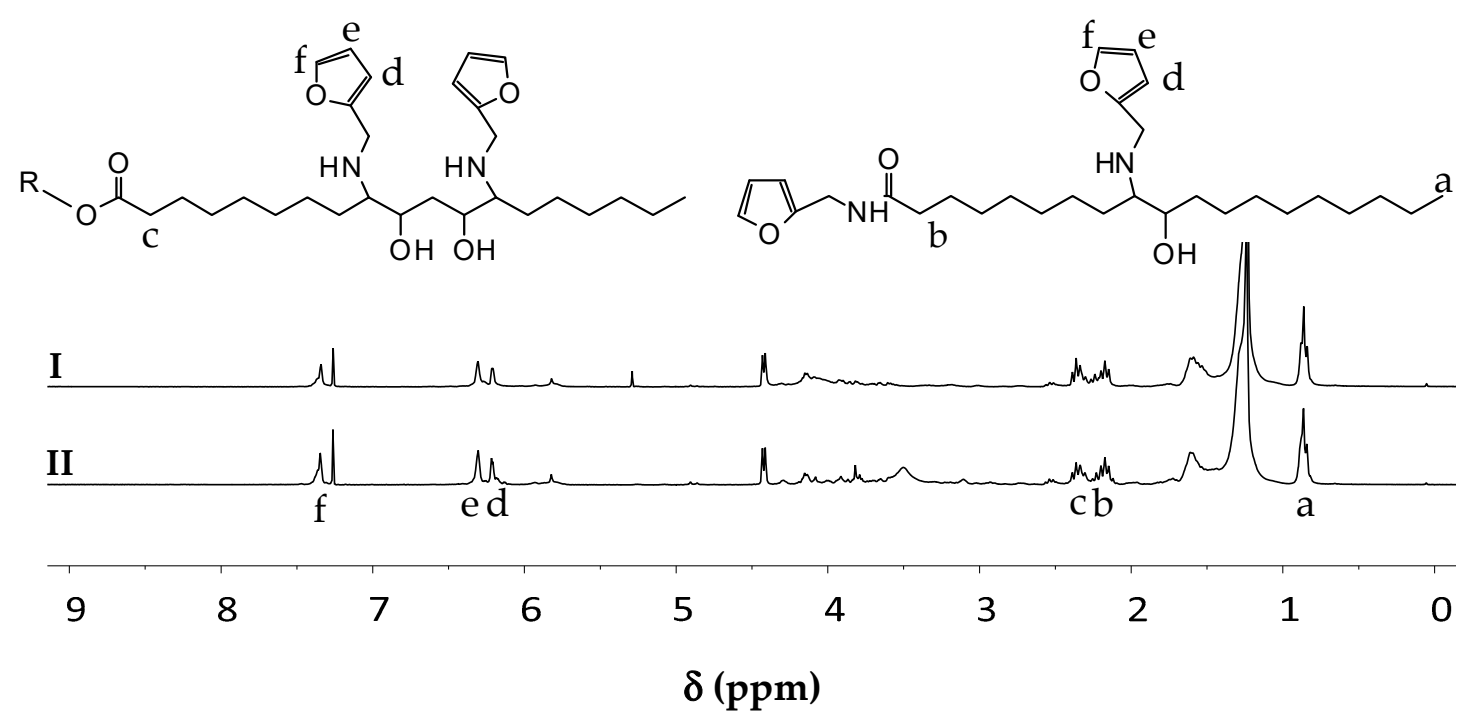

Figure 4. Proton NMR spectra of: (I) furan-functionalized jatropha oil and (II) furan-functionalized sunflower oil. 


\subsection{Model Reactions}

In order to synthesize the thermally reversible polymers, furan-functionalized oils were reacted with bismaleimides via the DA reaction. In this work, aromatic and aliphatic bismaleimides were mixed in order to tailor the mechanical properties of the polymers. Indeed, a previous work carried out on ethylene/propylene copolymers functionalized with furan and cross-linked in the same way (i.e., with bismaleimide) demonstrated a detectable influence of the cross-linker structure on the final properties [37]. To provide more insight to the DA reaction between furan groups and each of the bismaleimides, 2,5-dimethylfuran as a model furan compound was reacted with each of the aromatic and aliphatic bismaleimides (Figure 5).
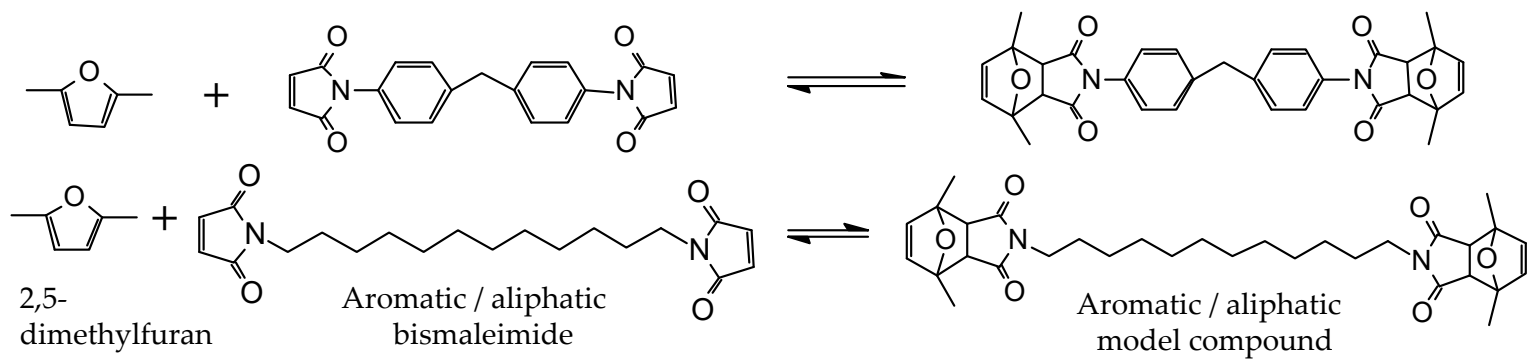

Figure 5. Model reaction scheme.

Each of the bismaleimides was mixed with excessive 2,5-dimetylfuran without an additional solvent, and stirred at $50{ }^{\circ} \mathrm{C}$ for $24 \mathrm{~h}$. The extent of the DA and rDA reactions and their dependency towards temperature were investigated by using FTIR spectrometry during two heating-cooling cycles between $50-110^{\circ} \mathrm{C}$ (Supplementary Figure S1). This range of temperature was preferred because it was expected to accommodate both reactions while avoiding the degradation of the model compounds which was found to occur above $110{ }^{\circ} \mathrm{C}$ (not shown for brevity), and minimizing the evaporation of 2,5-dimethylfuran (boiling point of $92-94{ }^{\circ} \mathrm{C}$ ). The peak assigned to the $\mathrm{C}-\mathrm{O}-\mathrm{C}$ group of DA adduct $[38,41]$ was recognized at around $1197 \mathrm{~cm}^{-1}$ for the reaction with aromatic bismaleimide, and around $1170 \mathrm{~cm}^{-1}$ for the one with aliphatic bismaleimide (Figure 6). These peaks were divided by the area of the peak related to the asymmetric $\mathrm{C}=\mathrm{O}$ stretching vibration of maleimide and $\mathrm{DA}$ adduct $[42,43]$ at $1700 \mathrm{~cm}^{-1}$. In the case of the aliphatic model, this calculation led to very small values. In order to make the observation easier, these numbers were further normalized to the initial peak areas of each sample.

Bismaleimides present in the form of powders and they are soluble in 2,5-dimethylfuran. After the mixtures were stirred at $50^{\circ} \mathrm{C}$ for $24 \mathrm{~h}$, the aromatic model compound appeared as an opaque pasty material, while the aliphatic model compound was a transparent brownish liquid. The DA reaction occurred during stirring, as the DA adduct signal was visible at the beginning of the identification by using FTIR. The changing peak areas attributed to the DA signal of the aromatic and aliphatic models are displayed in Figure 6. Both the samples demonstrate changes that indicate the occurrence of the DA and rDA reactions. During heating (zone I and III), the DA adduct signal weakened, while it was strengthened during cooling (zone II and IV).

The changes of the DA adduct signal of the aromatic model was more dramatic, implying that both DA and rDA reactions occurred with high yield. Although the mixture was heated to above the boiling point of 2,5-dimethylfuran, it did not evaporate much, probably because it was trapped in the structure of the pasty material. 
(a)

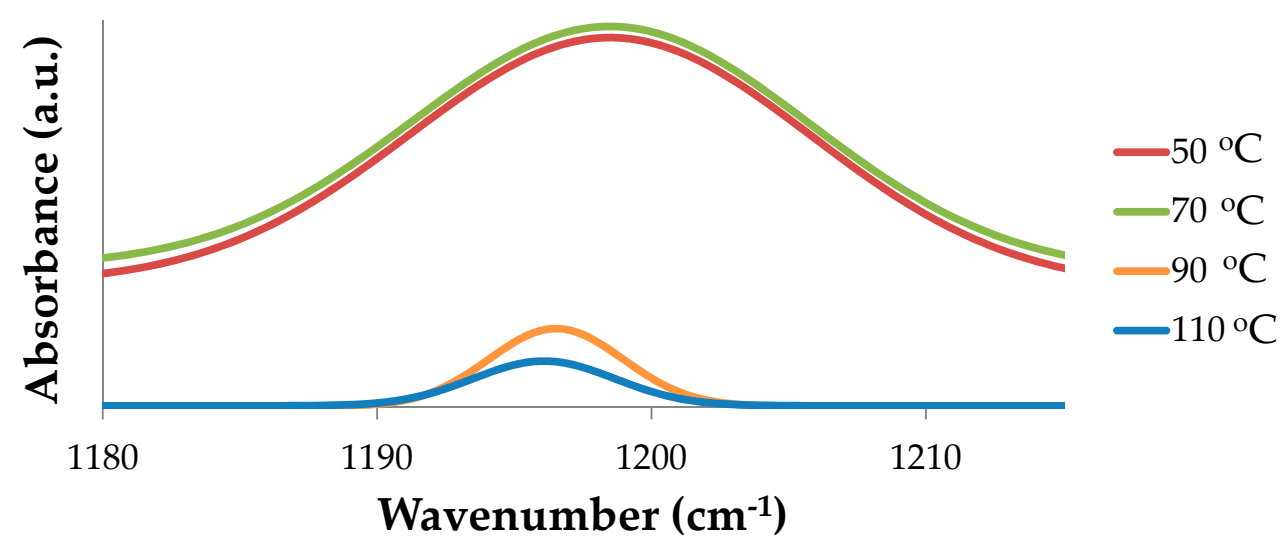

(b)

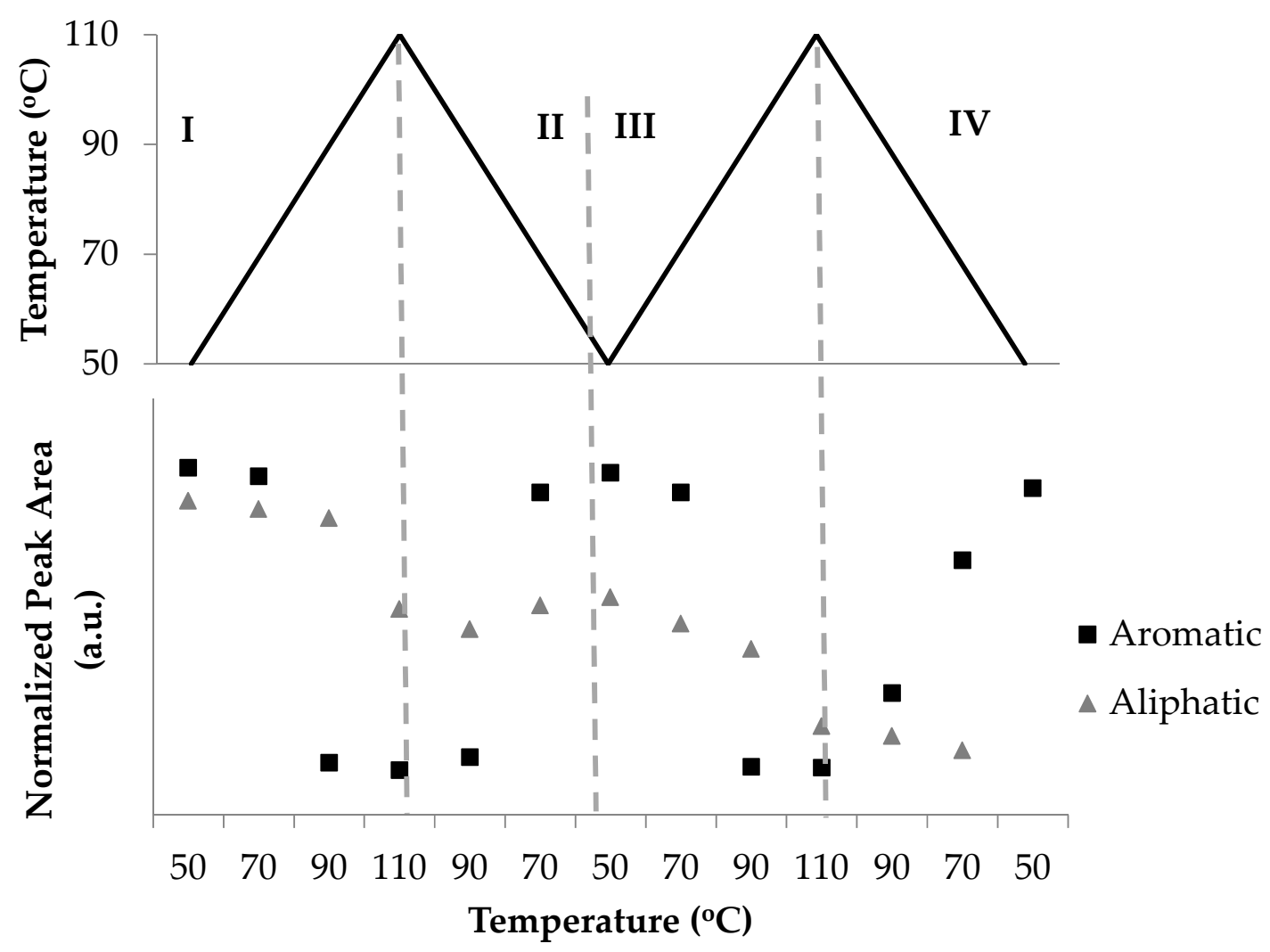

Figure 6. (a) Changes in the FTIR peak assigned to the $\mathrm{C}-\mathrm{O}-\mathrm{C}$ group of the DA adduct in the first heating cycle of 2,5-dimethylfuran with the aromatic bismaleimide during the first heating; and (b) changes in the peak area of the DA adduct peak of reaction products with aromatic and aliphatic bismaleimide.

The aliphatic model also demonstrated reversibility, as the peak area of the DA adduct decreased during heating (zone I and III), and increased during cooling (zone II). However, the overall trend of this signal change was negative, implying that the amount of adduct decreased over the thermal cycles. The physical appearance of the aliphatic model compound did not change during the stirring process and the intensity of the DA adduct signal was low, which might indicate that DA reaction proceeded to a low extent. Free 2,5-dimethylfuran might evaporate during the thermal cycles, leaving a decreasing amount available for the DA reaction. 


\subsection{Synthesis and Characterization of Thermally Reversible Networks}

Thermally reversible networks were synthesized by reacting the furan-functionalized oils with a mixture of the bismaleimides at different compositions, as explained in Table 1. The formation of the polymeric materials is expected to result from DA reaction between the furan groups in the modified oil and the bismaleimides. Polymers with different rigidities were retrieved as the product of these reactions (Figure 7). As expected, higher concentration of aliphatic bismaleimide used in the reaction generated more flexible polymers [37]. With the same composition of bismaleimides, jatropha-based polymers were more flexible than their sunflower ones. Sunflower-based polymer with $60 \%$ of aliphatic bismaleimide was too rigid to be bent, while the similar jatropha-based polymer can form a curve from bending. This difference arises from the higher content of triglyceride structure retained in the modified jatropha oil. Higher triglyceride contents induced longer backbone and lower cross-linking density, and hence higher flexibility of the polymers. The storage modulus of the polymers at $20^{\circ} \mathrm{C}$ range between $1.56 \times 10^{7} \mathrm{~Pa}$ to $8.80 \times 10^{7} \mathrm{~Pa}$, except for SF- $60-40$ that was too brittle to undergo thermo-mechanical measurement. The storage modulus curves of the polymers can be found in Supplementary Figure S2.

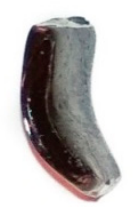

$\mathrm{J}-40-60$

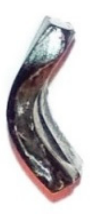

$\mathrm{J}-60-40$

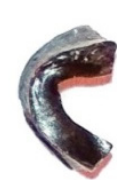

$\mathrm{J}-80-20$

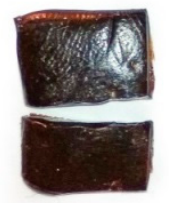

SF-60-40

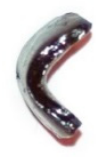

SF-80-20 SF-100-0

Figure 7. Polymers synthesized with different bismaleimide composition. The codes J and SF refer jatropha or sunflower oil, the numbers describe the percentage of aliphatic and aromatic bismaleimides respectively.

The difference of the polymer structure also influenced their $\mathrm{T}_{\mathrm{g}}$, as described in Figure 8. Sunflower-based polymers possess a higher $T_{g}$ than the jatropha-based ones due to the difference in their cross-link densities. Higher cross-link density means that the molecular segments between cross-links are shorter, thus the segmental mobility is hindered. Higher aromatic bismaleimide content also results in higher $\mathrm{T}_{\mathrm{g}}$ of the polymers because its structure is more rigid and inflexible compared to the aliphatic bismaleimide. Both the higher cross-link density and the aromatic content increase the amount of thermal energy needed to enable molecular mobility under dynamic conditions, thus increasing the temperature at which the molecules become more mobile [44].

The composition of the aliphatic and aromatic bismaleimides was found to influence the mechanical properties of the polymers. In a previous work, furan-derivatized jatropha oil was cross-linked with only the aromatic bismaleimide, generating materials too brittle for practical applications [40]. Aliphatic bismaleimide was found to increase the flexibility of the materials, which is in agreement with a recent work where the bismaleimide was used to cross-link EPM rubber [37]. It was also found that the composition of the bismaleimides can be adjusted to obtain polymers with the desired flexibility.

The thermo-reversibility of the polymers was confirmed by using FTIR during 2 heating-cooling cycles. The spectra were normalized to the unreacted alkyl signal $[45,46]$ at $2854 \mathrm{~cm}^{-1}$. Figure 9 displays a series of FTIR spectra taken during the first heating of the J-40-60 polymer (zone I in Figure 10). The signal attributed to the ether group in the DA adduct [38,47] at around $1185 \mathrm{~cm}^{-1}$ decreased with increasing temperature, while the furan ring breathing signal [47] at $1011 \mathrm{~cm}^{-1}$ and maleimide ring deformation signal [41] at $693 \mathrm{~cm}^{-1}$ increased. The observation of the DA and rDA reactions occurring in the samples was focused on the changes of these signals. 


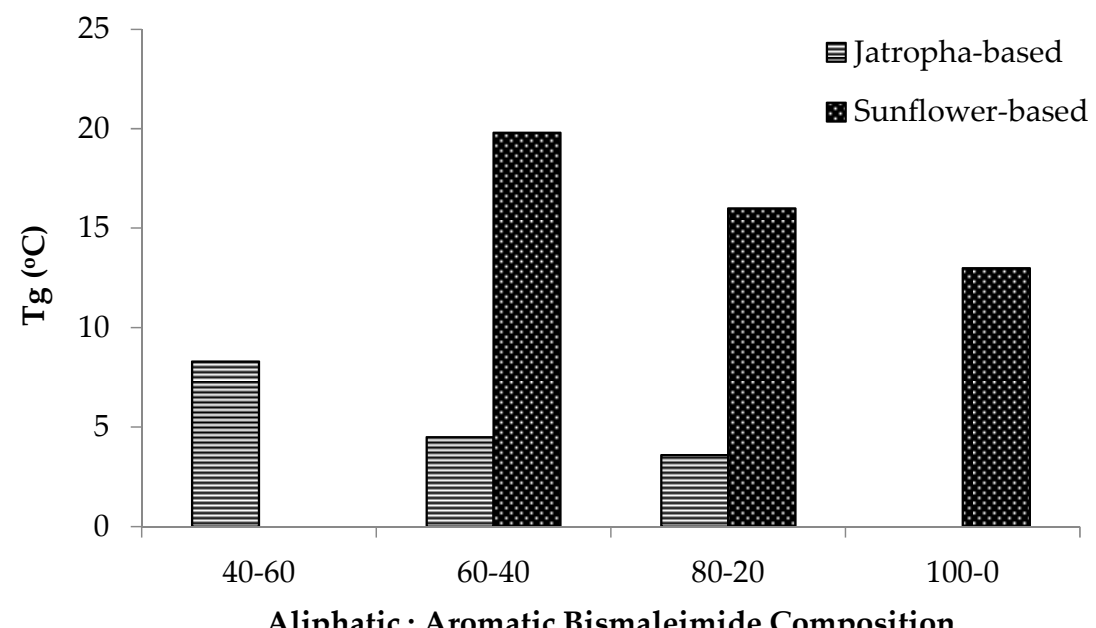

Figure 8. Glass transition temperature of jatropha- and sunflower-based polymers according to the bismaleimide compositions.
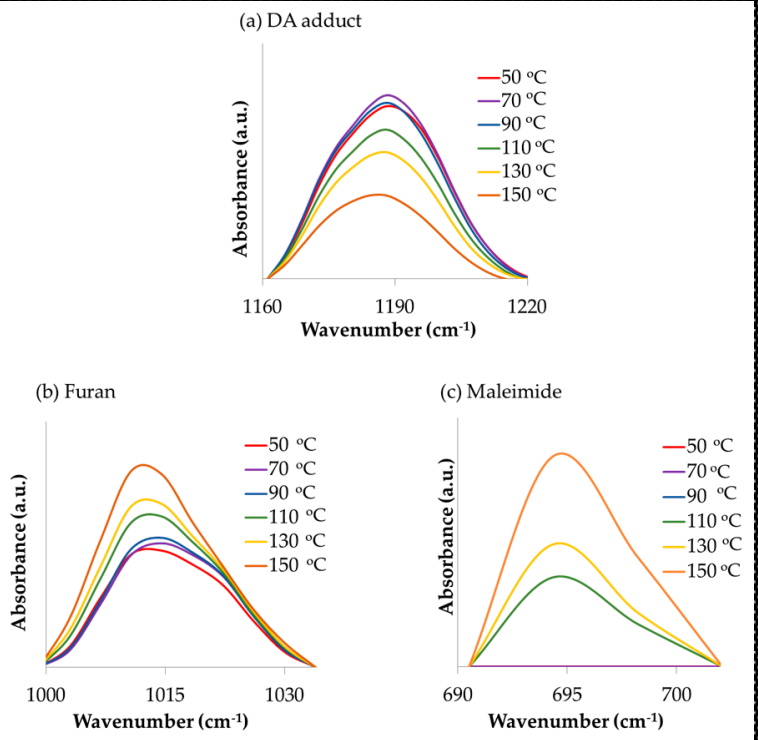

Figure 9. FTIR peaks of polymer J-40-60 taken at different temperatures during heating from $50{ }^{\circ} \mathrm{C}$ to $150{ }^{\circ} \mathrm{C}$, assigned to the (a): DA adducts, (b): furans, and (c): maleimides.

Further changes on the DA adduct during two cycles of heating and cooling of the polymers can be observed in Figure 10. It is worthwhile to note that the intensities of this peak decreased as the portion of aliphatic bismaleimide in the polymers was increased. Since the areas and the changes of peaks related to the furans and maleimides are similar for all samples, it can be expected that the differences in DA adduct peaks arise from the structural difference between the aliphatic and aromatic bismaleimides. In order to render the observations in the peak at $1185 \mathrm{~cm}^{-1}$ quantitatively, the curves in Figure 10 were normalized so that all polymers exhibit similar intensities.

The area of the DA adduct peak at $1185 \mathrm{~cm}^{-1}$ decreased during heating (zone I and III) and increased during cooling (zone II and IV). At the beginning of zone I, the peak area increased, indicating that the DA reaction took place until the temperature reached $70{ }^{\circ} \mathrm{C}$ or $90^{\circ} \mathrm{C}$. After reaching the maximum value, the areas gradually decreased while the temperature was increased to $150{ }^{\circ} \mathrm{C}$, implying that the rDA reaction occurred. The areas increased again during cooling (zone II) and reached their new maximum at $70{ }^{\circ} \mathrm{C}$ on the second heating, then slightly decreased at $50{ }^{\circ} \mathrm{C}$, then bounced back up at $70^{\circ} \mathrm{C}$. The trend was repeated in the second heating-cooling cycle, implying that the reactions can be performed repeatedly. However, the maximum peak area decreased with more cycles, implying that 
the amount of DA adduct was reduced. The peak area corresponds to the ether group of the DA adduct, thus the decrease of this signal might suggest that a portion of the ether was no longer present, probably because the adduct was aromatized [38,48]. As shown in Figure 11, the decrease of this signal is visible when comparing its maximum intensity at $90{ }^{\circ} \mathrm{C}$, in the first heating and second cooling cycles. However, there are other possible explanations to this trend, as revealed by other data obtained in this study.

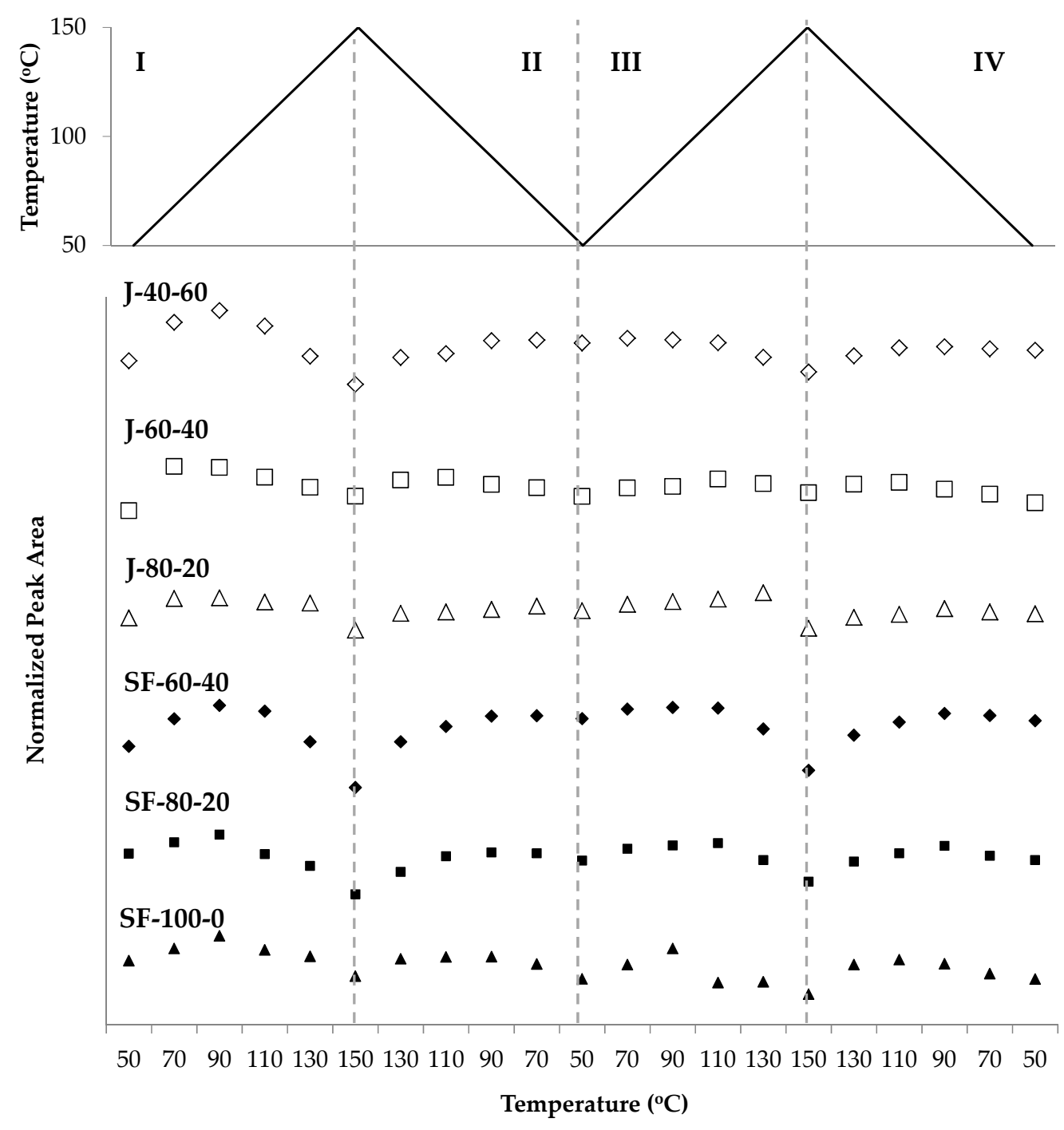

Figure 10. The changing peak areas attributed to the $\mathrm{C}-\mathrm{O}-\mathrm{C}$ group in the DA adduct at $1180 \mathrm{~cm}^{-1}$ during heating and cooling of the jatropha oil- and sunflower oil-based polymers, normalized to the peak area of the unreacted methyl at $2854 \mathrm{~cm}^{-1}$.

An interesting phenomenon is clearly observed in Figure 10 . At $50{ }^{\circ} \mathrm{C}$, the DA adduct was expected to be at its maximum amount as a consequence of the DA reaction, however, the correlating peak area at this temperature is always lower than at $70{ }^{\circ} \mathrm{C}$. It appears that the rDA reaction was dominant at $50^{\circ} \mathrm{C}$. A possible explanation for this phenomenon is the existence of two stereoisomers of the DA adduct, the endo and exo isomers. The endo isomer undergoes rDA reaction at lower temperature [49-51], in our case, at around $50{ }^{\circ} \mathrm{C}$, resulting in the decrease of DA adduct peak area. During heating to $70{ }^{\circ} \mathrm{C}$, the free furan and maleimide groups subsequently reacted to form exo isomers [49], increasing the DA adduct peak. Further heating triggered the rDA reaction of the exo adducts starting at above $90^{\circ} \mathrm{C}$ in most of the polymer samples. 


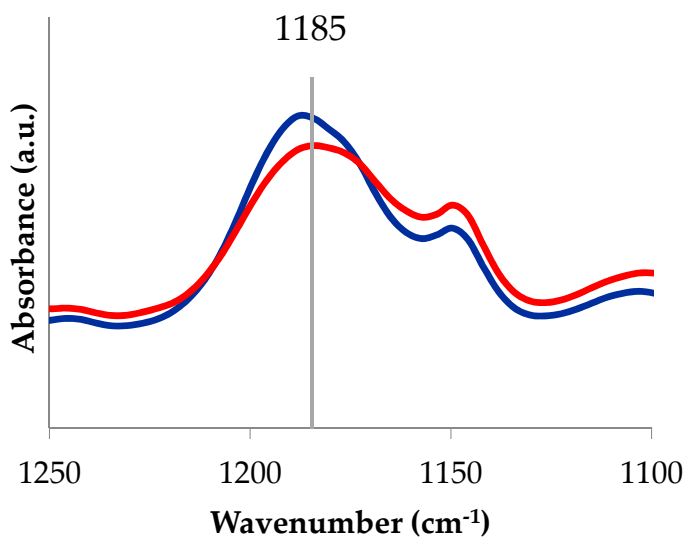

$-1^{\text {st }}$ heating, $90^{\circ} \mathrm{C} \quad 2^{\text {nd }}$ cooling, $90^{\circ} \mathrm{C}$

(a)

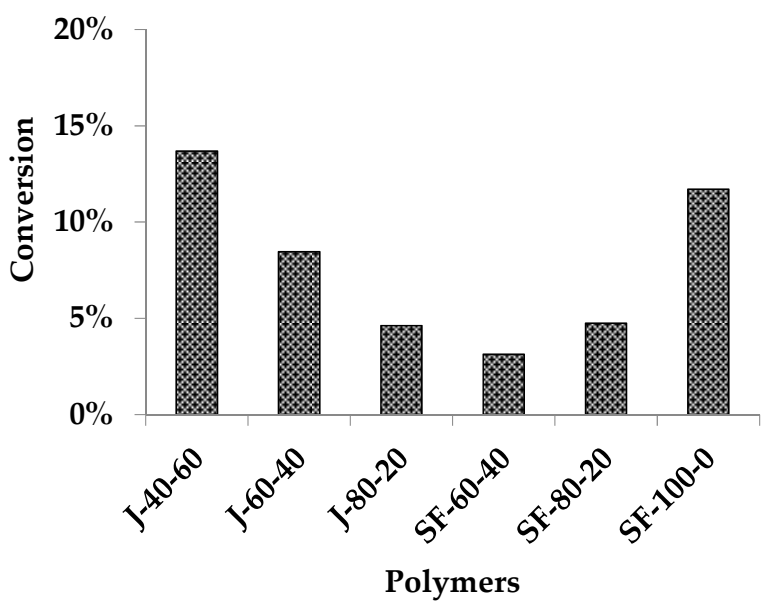

(b)

Figure 11. FTIR curves of polymer J-40-60 describing changes in signals related to the DA adduct, measured at $90^{\circ} \mathrm{C}$ on the first heating and second cooling cycles (a). The peak at $1185 \mathrm{~cm}^{-1}$ corresponds to the $\mathrm{C}-\mathrm{O}-\mathrm{C}$ group, while the one at $1070 \mathrm{~cm}^{-1}$ represents the furan in-plane $\mathrm{C}-\mathrm{H}$ deformation. The bar graph (b) displays how much of the peak areas were reduced during the measurement.

The changes of the furan peak area at around $1011 \mathrm{~cm}^{-1}$ support the idea of DA and $\mathrm{rDA}$ reactions occurring during the measurement (Figure 12). The furan peak areas increased during heating (zone I and III), implying that the furans were formed in the rDA reaction. The peak area reached its maximum at $150{ }^{\circ} \mathrm{C}$ and was reduced during cooling, with the same trend took place in the second cycle. Measured furan peak area in the second cycle (zone III) was slightly higher than in the first (zone I), indicating that the amount of unreacted furan was higher than that in the first. This condition is in agreement with the trend in Figure 10, indicating that less DA adduct was formed in the second heating-cooling cycle.

The maleimide signal located at around $693 \mathrm{~cm}^{-1}$ of all polymers also demonstrated the thermo-reversibility of the polymers (Figure 13). The signal increased during heating (zone I and III), revealing that the maleimides were formed in the rDA reaction. The signal decreased during cooling (zone II and IV), implying that the maleimides were consumed in the DA reaction. This signal was visible at temperatures above $90{ }^{\circ} \mathrm{C}$ for most polymers, indicating that the rDA reaction was dominant in these temperatures. In contrast to the furan signal, the maleimide signal was not visible below $90^{\circ} \mathrm{C}$, which can be interpreted as a complete or nearly-complete conversion of the maleimides. On the other hand, the furan signal was always visible, revealing that they were not entirely consumed in the DA reaction.

Another observed trend in Figure 13 is that the maleimide peak area was lower in the second cycle than the first. This fact supports the hypothesis that the DA reaction was less prominent in the second cycle. The amount of bismaleimide was reduced, thus there was less of this group available for the DA reaction, hence the number of unreacted furans increased. Decreasing maleimides amount might be caused by homopolymerization of this group [52]. Maleimides can react with one another above their melting point [53], and the experiment temperature reached close or above their melting points (156-158 ${ }^{\circ} \mathrm{C}$ for the aromatic bismaleimide [54] and $103^{\circ} \mathrm{C}$ for the aliphatic bismaleimide [37]). Another evidence of maleimide homopolymerization is the decreasing peak area of signals at $828 \mathrm{~cm}^{-1}$, attributed to the $\mathrm{C}=\mathrm{C}$ bond of the maleimide ring $[55,56]$, measured at $150{ }^{\circ} \mathrm{C}$ in the first and second heating of the measurement. A sample of the decreasing peak areas of maleimides-related signals is given in Figure 14. 


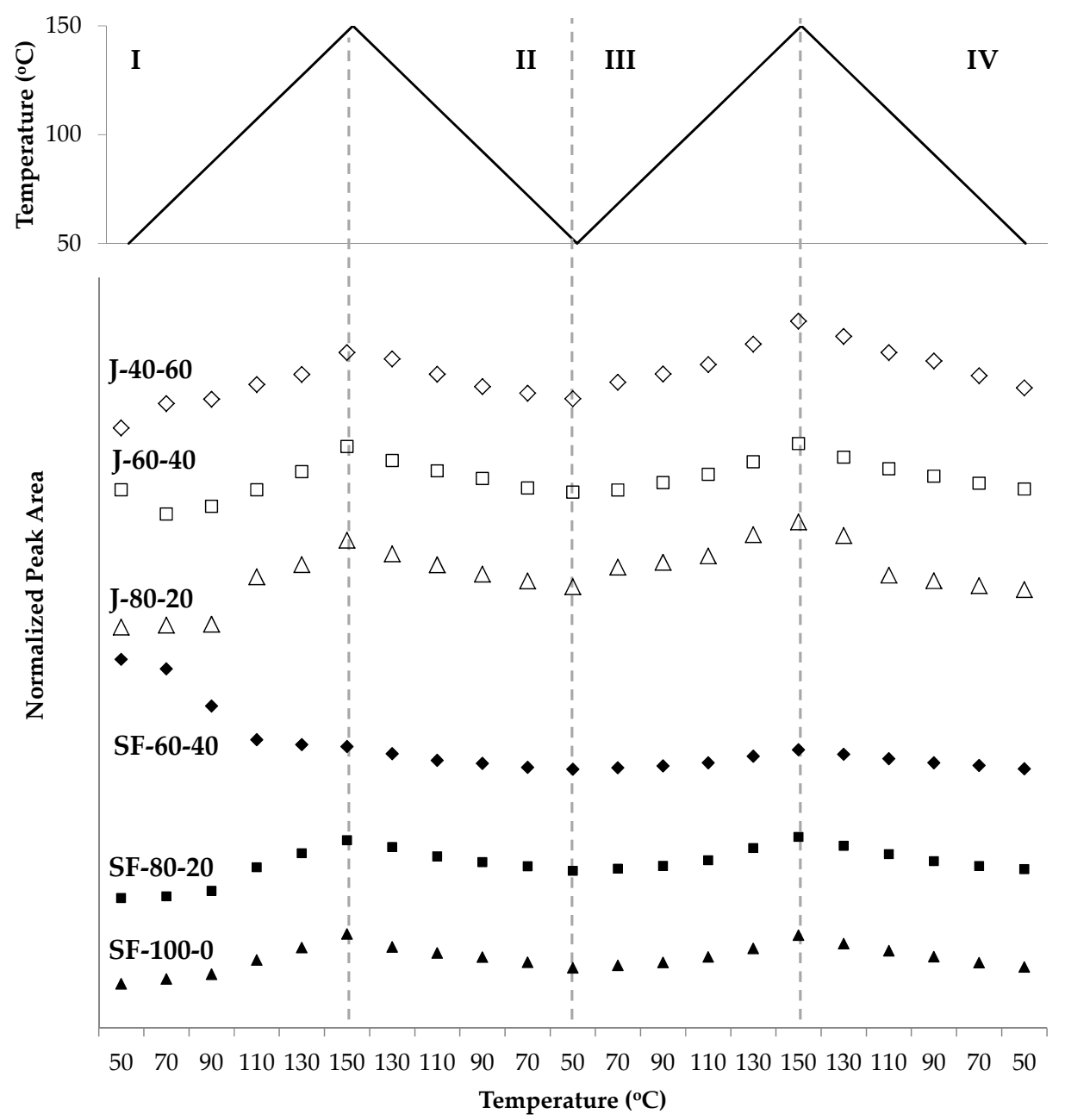

Figure 12. The changing area of a peak related to furans at $1012 \mathrm{~cm}^{-1}$ during two heating-cooling cycles of the jatropha oil- and the sunflower oil-based polymers.

Polymer reversibility was also observed during measurements by using DMA. Since the polymers were deformed at temperatures above $55^{\circ} \mathrm{C}$, the measurements were performed by using material pockets. This device was designed to enable the measurement of thermo-mechanical transitions of powders in their native forms by using DMA [57], therefore it is also applicable in non-self-supporting samples such as polymers above their softening point. The absolute value of storage, loss modulus, and $\tan \delta$ did not reveal the real properties of the material due to the use of material pockets, however, the transition temperature data is reliable. Therefore, the $\tan \delta$ curves are used to observe the transition temperatures of the polymers during the measurement. The values of $\tan \delta$ are denoted in arbitrary units (a.u.).

Figure 15 demonstrates the transitions observed during the DMA measurement of polymer J-80-20 and SF-100-0 with three heating-cooling cycles. The peaks of $\tan \delta$ demonstrate the rDA reaction during heating (left) and DA reaction during cooling (right). The peaks of the curves shift to the right, demonstrating the increasing tempeartures at which DA and rDA reaction took place with the thermal cycles. This tendency might be related to the aromatization of the DA adduct or homopolymeryzation of the maleimides [52], both producing irreversible cross-links [48,58-60]. These networks reduced the mobility of the materials, and thus restraining the DA and $\mathrm{rDA}$ reactions to occur. The trend also applied to other polymer samples, which are summarized in Figure 16. 


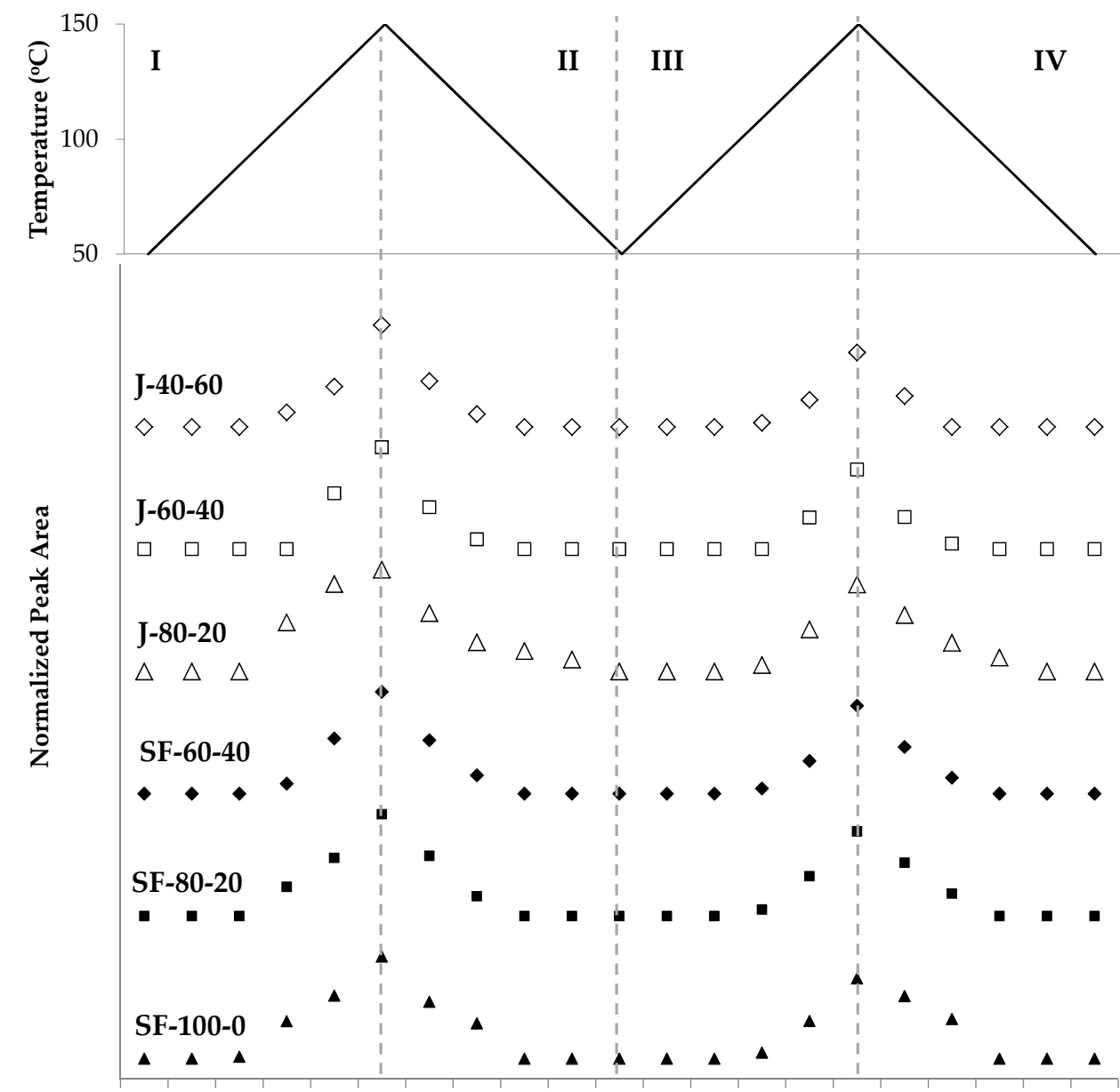

$50 \quad 70 \quad 90110130150130110 \quad 90 \quad 70 \quad 50 \quad 70 \quad 90110130150130110 \quad 90 \quad 70 \quad 50$

\section{Temperature $\left({ }^{\circ} \mathrm{C}\right)$}

Figure 13. The increase and decrease of peak areas assigned to maleimides during heating and cooling of the jatropha oil- and the sunflower oil-based polymers.

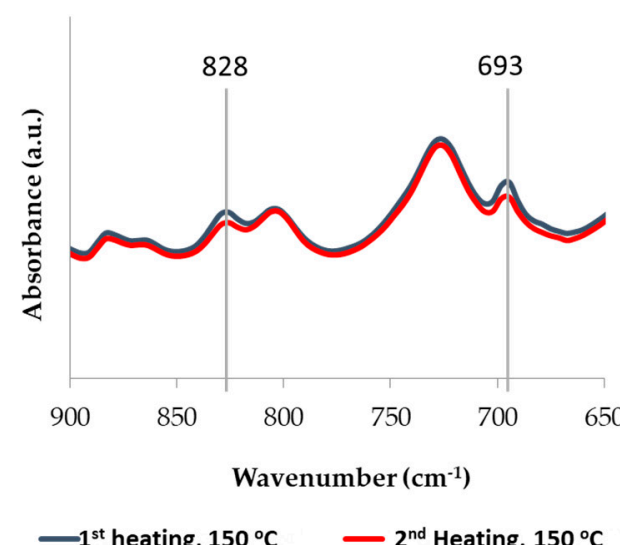

(a)

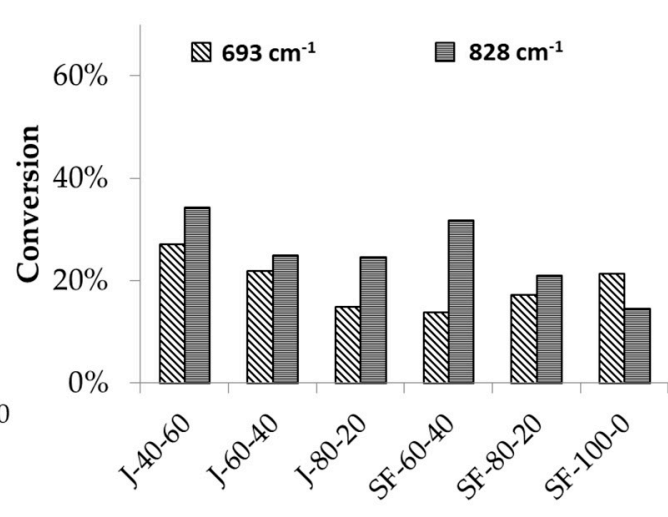

Polymers

(b)

Figure 14. FTIR curves of polymer J-80-20 displaying changes in signals related to the maleimides, measured at $150{ }^{\circ} \mathrm{C}$ on the first heating and second cooling cycles (a). The peak at $828 \mathrm{~cm}^{-1}$ corresponds to the $\mathrm{C}-\mathrm{C}$ double bond, while the one at $693 \mathrm{~cm}^{-1}$ represents the ring deformation. The bar graph explains how much of the peak areas were reduced during the measurement $(\mathbf{b})$. 
(a) SF-100-0 Heating

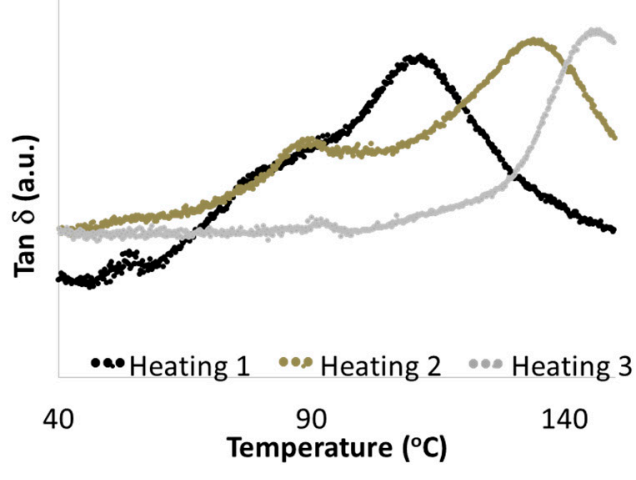

(c) J-80-20 Heating

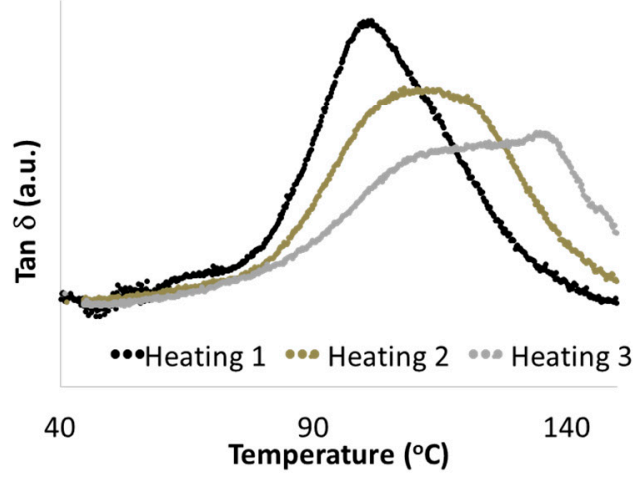

(b) SF-100-0 Cooling

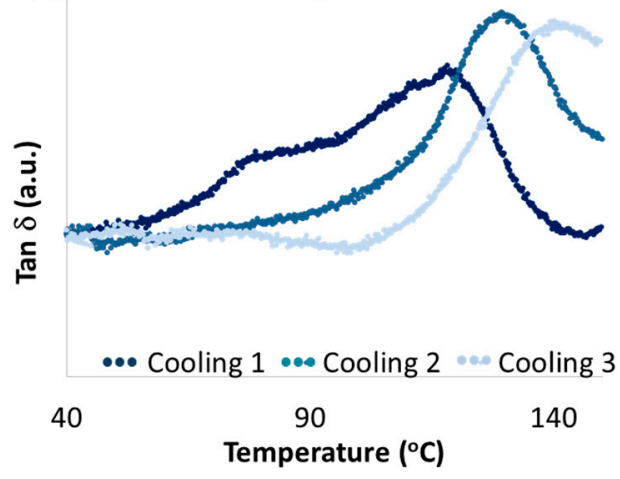

(d) J-80-20 Cooling

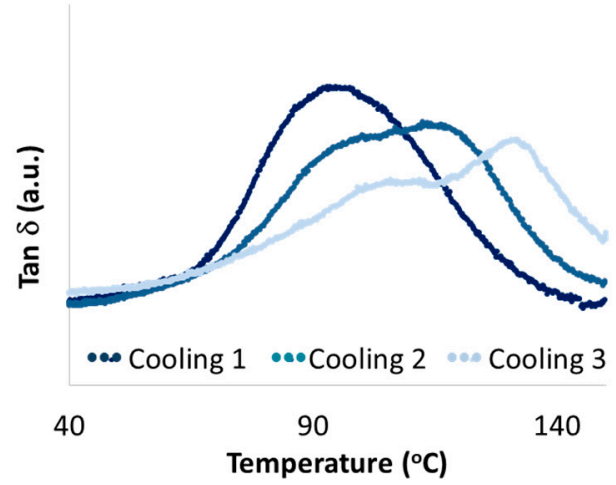

Figure 15. DMA curves showing changing temperatures of the rDA and DA reactions obtained in measurements with 3 heating-cooling cycles. The curves were taken during (a): SF-100-0 heating cycles, (b): SF-100-0 cooling cycles, (c): J-80-20 heating cycles, and (d): J-80-20 cooling cycles.

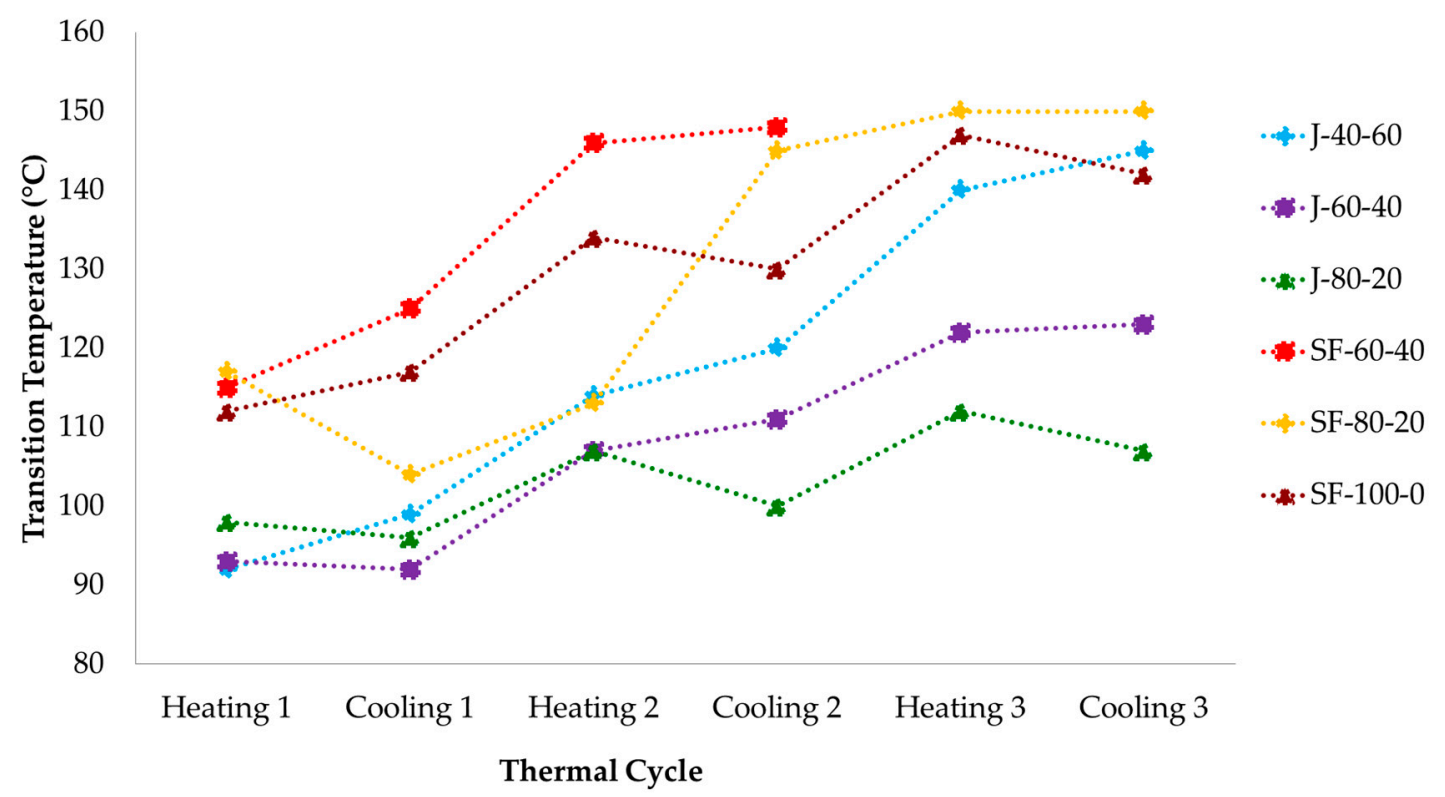

Figure 16. Transition temperatures observed in DMA measurements with 3 heating-cooling cycles. Lines are guides for the eye.

Some shoulders appeared at temperatures between $60^{\circ} \mathrm{C}$ and $90{ }^{\circ} \mathrm{C}$ on both of tan $\delta$ curves of SF-100-0 and heating of J-80-20 in Figure 13. These shoulders indicate that there are other transitions 
than the aforementioned DA and rDA reactions. Since these transition occurred at lower temperatures than the main transitions, it can be expected that these are related to the DA and rDA reactions of the endo adduct $[49,50]$. During heating, the shoulders revealed that there was a slight drop of the storage modulus, which can be related to the rDA reaction of the endo DA adduct into furans and maleimides. During cooling, the shoulders might suggest the formation of endo DA adducts. These events may correlate with the trend in Figure 10, in which the amount of the adduct was reduced at around $50{ }^{\circ} \mathrm{C}$. However, the FTIR spectra demonstrate the re-forming of DA adducts during heating, while the DMA curves display a continuous decrease in storage modulus (Figure S3 of the Supplementary Materials). There are several possible explanations for this event, i.e., the DA reaction took place at a lower extent under dynamic condition, or the influence of the DA reaction on the storage modulus was very low compared to the softening of the material due to a temperature increase.

Figure 16 includes the summary of the transition temperatures from the DMA measurement, which are related to the DA and rDA reactions. All polymers demonstrated similar trend of ascending transition temperatures with increasing number of heating-cooling cycles. This trend might indicate that by exposing the polymers to more thermal cycles, an increasing portion of the polymers became irreversibly cross-linked, thus inhibit both reactions. This tendency is in agreement with the data extracted from FTIR spectra on Figure 6 describing that the amount of the adducts were reduced during the measurement. In general, the samples prepared from sunflower oil showed slightly higher transition temperatures than those derived from jatropha oil. The higher cross-link density of the sunflower-based polymer might require a higher temperature for the DA and $\mathrm{rDA}$ reactions to occur [61].

Polymers with aliphatic bismaleimide content below $80 \%$ showed only one transition temperature on each cycles. When the aliphatic bismaleimide content was increased to $80 \%$, two transitions were observed (Figure 15). However, the polymer cross-linked with 100\% aliphatic bismaleimide returned to only having one transition on each cycle. This finding might suggest that at a high concentration of the aliphatic bismaleimide, each of the bismaleimide underwent the DA chemistry separately. The separation was observed at the second and third cycles during the measurement of polymer J-80-20 (Figure 17). On the contrary, the separation of polymer SF-80-20 was found from the early cycles of the measurement (not shown for brevity). In the third heating and cooling cycle of SF-80-20, the transitions at higher temperatures were not observed because they seemed to occur above the measurement range.

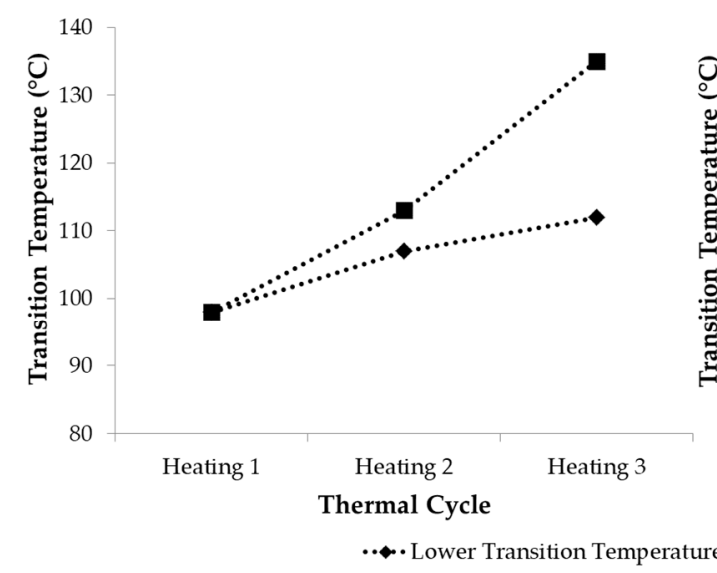

(a)

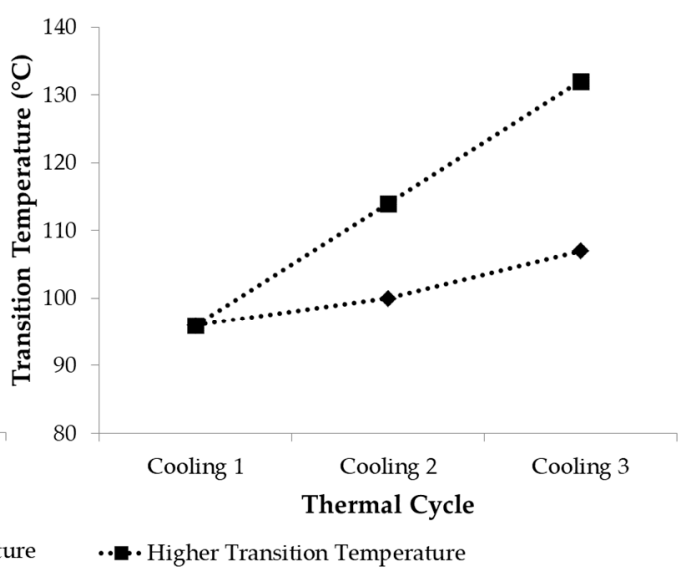

(b)

Figure 17. Two transition temperatures observed during the DMA measurement of polymer J-80-20 (a) related to the $\mathrm{rDA}$ reaction during the 2nd and 3rd heating; and (b) related to the DA reaction during 2nd and 3rd cooling. Lines are guides for the eye.

The samples used in DMA measurements with $0,1,2$, and 3 heating cycles were immersed for 1 day in THF with a mass ratio of 1:20 of polymers to the solvent. The insoluble parts of the polymers were 
collected and the masses were compared to the mass of the original samples. The samples that were not analyzed by using DMA were totally soluble. The insoluble portion of the samples increased with the number of thermal cycles (Figure 18). These insoluble materials are cross-linked polymers which might be the products of the DA adduct aromatization or maleimide homopolymerization [48,58-60].

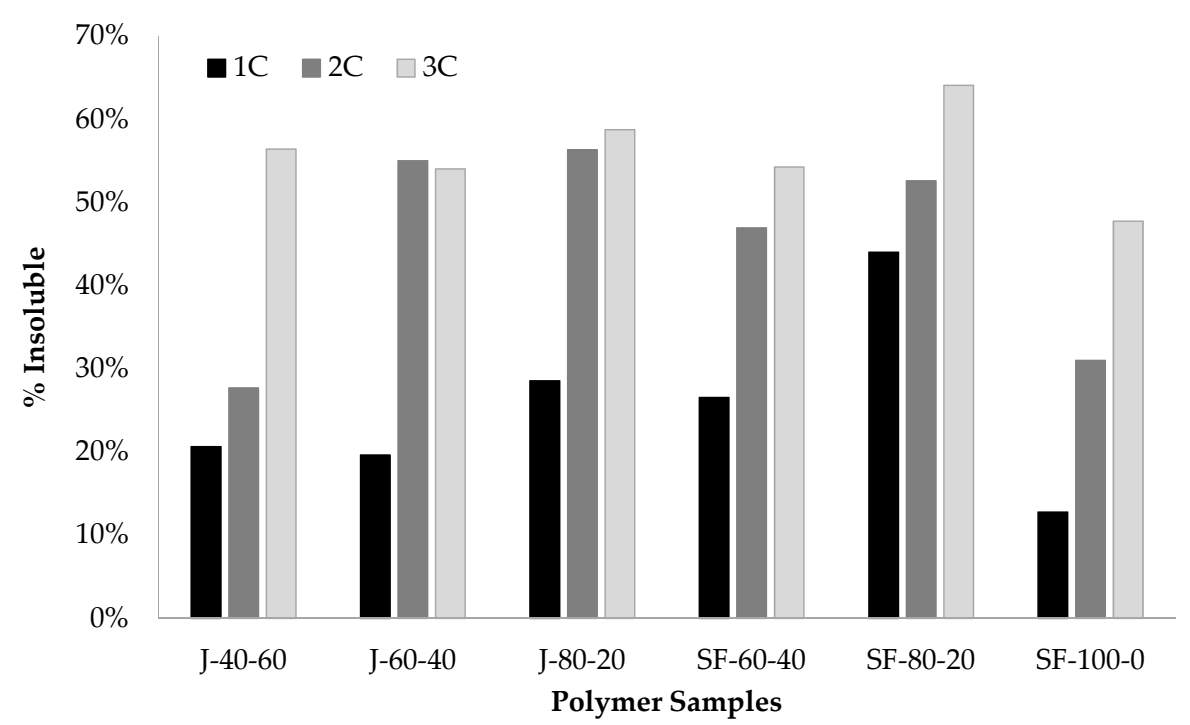

Figure 18. The percentage of insoluble polymer samples after DMA measurements with 1, 2, and 3 heating-cooling cycles.

The procedures performed to study the occurrence of the DA chemistry in the polymers revealed information that are in agreement with one another. Changes in the relevant signals of the FTIR spectra indicated that the DA and rDA reactions occurred in the polymers, including the possible occurrence of the endo and exo stereoisomers. Moreover, the changes in the mechanical properties in the DMA curves were in agreement with the FTIR spectra. Both characterizations also suggested that both reactions took place repeatedly during repeated thermal cycles, nevertheless, the reversibility decreased during the measurement. The trend is also found in other studies involving the furan and maleimide pair, in which the DA adduct underwent aromatization or maleimides homopolymerization [48,52,58]. This conclusion is supported by the occurrence of insoluble solids in the samples after the DMA measurement, as both side reactions resulting in irreversibly cross-linked polymers $[48,59,60]$. The literature suggested that both aromatization and maleimide homopolimerization occur at elevated temperatures. Therefore, reprocessing the thermally reversible polymers at lower temperatures might reduce the formation of irreversible cross-links.

Further experiments were performed to explore the possibilities in applying the polymers into technical use. The polymers J-40-60 and SF-80-20 were used to bind two aluminum sheets. The bonding strength was examined according to ASTM D1876-08 with some modifications. The bonded sheets were pulled apart in a $180^{\circ}$ direction using a tensile tester, and the average bonding strength was calculated. As a comparison, a commercial mounting glue was also tested using the same procedure.

The average peel resistance of the adhesives is given in Figure 19. The peel resistance of J-40-60 and SF-80-20 exceeded the performance of the commercial mounting glue, therefore, the polymers can be considered as a potential adhesive material. Polymer J-60-40 showed higher bonding strength than SF-80-20. J-40-60 contained a higher concentration of the aromatic bismaleimide, thus it was more rigid than SF-8-20. This result is in agreement with a literature stating that the more flexible polymers usually perform lower cohesive strength than the rigid ones [62]. This result is an evidence of how the polymers are potentially applicable as adhesives, even without modification. The correlation between the structure and the bonding strength can be used as a guidance in designing the material to tune its performance. 


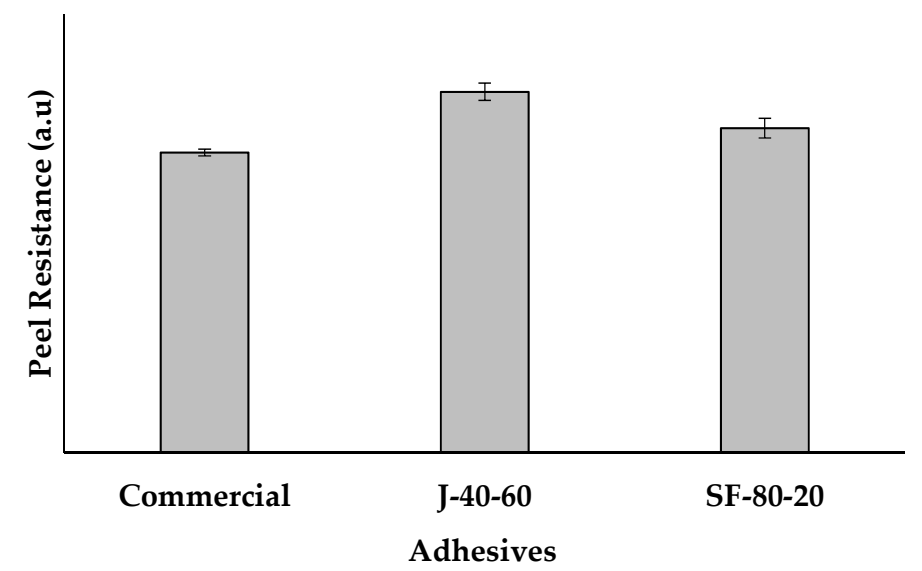

Figure 19. The average peel bonding strength of adhesives made of the polymers J-4-60 and SF-80-20, compared to a commercial mounting glue.

\section{Conclusions}

Thermally reversible low cross-link density polymers were synthesized from vegetable oils containing different number of unsaturations, viz. jatropha and sunflower oils (3.6 and 4.5 C-C double bonds per triglyceride molecule). The oils were epoxidized to fully convert the double bonds into epoxide groups. The epoxidized oils were reacted with furfurylamine in order to attach furan groups into the structure according to an optimized condition developed for epoxidized jatropha oil. The condition ensured minimum conversion of the ester groups and maximum number of furans attached to the oil. However, the same condition did not work as well for epoxidized sunflower oil due to steric hindrance. There is more triglyceride structure retained in the jatropha-based monomer rather than in its sunflower counterpart (in average 2.36 compared to 2.00 esters/molecule), while the number of furans attached were less in the modified jatropha oil (2.57 compared to 3.42 furans/molecule).

Mixtures of aromatic and aliphatic bismaleimides were used to tailor the mechanical properties of the polymers, resulting in a series of polymers with different brittleness with $\mathrm{T}_{\mathrm{g}}$ ranging from 3.6 to $19.8^{\circ} \mathrm{C}$. The properties were influenced by the structure of the furan-functionalized oil and the composition of bismaleimides. Sunflower-based polymers were more brittle with higher $T_{g}$, due to their higher cross-link density. Higher aliphatic bismaleimide concentration lowered the $T_{g}$ and induced higher flexibility of the polymers.

Changes in the chemical structure and mechanical properties observed in FTIR and DMA measurements suggest that the Diels-Alder and retro-Diels-Alder reactions occurred in recurring thermal cycles. However, an increasing part of the polymers were irreversibly cross-linked with more thermal cycles, which might be caused by aromatization of the DA adduct and homopolymerization of the maleimide groups.

The polymers J-40-60 and SF-80-20 were successfully applied as adhesives, as shown by the results of T-Peel Test. The bonding strength of these polymers were better than a commercial mounting glue, with J-40-60 showing the best performance. The rigidity of the polymers was found to correlate with the bonding strength of the adhesives.

All in all, the present study clearly demonstrates the possibility to cross-link vegetable oil derivatives in a thermally reversible way, as already demonstrated in many other works. The obtained polymers were found to be applicable as adhesives with better performances than a commercial mounting glue. However, the presented data also clearly indicate the occurrence of side reactions that are typical of this DA chemistry and adduct. These side reactions influenced the thermal and mechanical behavior. Future studies might address a quantitative evaluation of these side reactions and possibly their use for designing novel materials displaying the possibility to thermally reversible or irreversible cross-linking as a function of the curing temperature. 
Supplementary Materials: The following are available online at http://www.mdpi.com/2073-4360/12/8/1708/s1, Figure S1: FTIR spectra of the aromatic and aliphatic model compound, at $50{ }^{\circ} \mathrm{C}$ of the first heating; Figure S2: Storage modulus of the polymers, measured without material pockets; Figure S3: The storage modulus of polymer $\mathrm{J}-80-20$ on the first heating and cooling cycle.

Author Contributions: Conceptualization, F.P.; methodology, F.Y. and R.K.B.; investigation, F.Y., J.H., and K.S.I.; resources, F.P.; writing—original draft preparation, F.Y.; writing—review and editing, F.P. and R.K.B.; supervision, F.P.; funding acquisition, F.Y. All authors have read and agreed to the published version of the manuscript.

Funding: The authors would like to show gratitude to RISET PRO (Research and Innovation in Science and Technology Project), Ministry of Research, Technology, and Higher Education, Republic of Indonesia, for partially funding this research.

Acknowledgments: F.Y. would like to gratefully thank Lorenzo M. Polgar and Robin R. Cerpentier for kindly preparing the 1,12-bis(maleimide)dodecane used in this study; and Felipe Orozco-Guiterrez for discussions.

Conflicts of Interest: The authors declare no conflict of interest.

\section{References}

1. Zhang, C.; Garrison, T.F.; Madbouly, S.A.; Kessler, M.R. Recent advances in vegetable oil-based polymers and their composites. Prog. Polym. Sci. 2017, 71, 91-143. [CrossRef]

2. Vilela, C.; Silvestre, A.J.D.; Gandini, A. Thermoreversible nonlinear diels-alder polymerization of furan/plant oil monomers. J. Polym. Sci. Part A Polym. Chem. 2013, 51, 2260-2270. [CrossRef]

3. Sousa, A.F.; Vilela, C.; Fonseca, A.C.; Matos, M.; Freire, C.S.R.; Gruter, G.-J.M.; Coelho, J.F.J.; Silvestre, A.J.D. Biobased polyesters and other polymers from 2,5-furandicarboxylic acid: A tribute to furan excellency. Polym. Chem. 2015, 6, 5961-5983. [CrossRef]

4. Lligadas, G.; Ronda, J.C.; Galià, M.; Cádiz, V. Renewable polymeric materials from vegetable oils: A perspective. Mater. Today 2013, 16, 337-343. [CrossRef]

5. Belgacem, M.N.; Gandini, A. Monomers, Polymers and Composites from Renewable Resources; Elsevier Ltd.: Oxford, UK, 2008; ISBN 9780080453163.

6. Hess, P.S.; O'Hare, G.A. Oxidation of Linseed Oil. Ind. Eng. Chem. 1950, 42, 1424-1431. [CrossRef]

7. Wexler, H. Polymerization of drying oils. Chem. Rev. 1964, 64, 591-611. [CrossRef]

8. De Viguerie, L.; Payard, P.A.; Portero, E.; Walter, P.; Cotte, M. The drying of linseed oil investigated by Fourier transform infrared spectroscopy: Historical recipes and influence of lead compounds. Prog. Org. Coat. 2016, 93, 46-60. [CrossRef]

9. Mallégol, J.; Gardette, J.-L.; Lemaire, J. Long-term behavior of oil-based varnishes and paints I. Spectroscopic analysis of curing drying oils. J. Am. Oil Chem. Soc. 1999, 76, 967-976. [CrossRef]

10. Igwe, I.O.; Ogbobe, O. Studies on the properties of polyesters and polyester blends of selected vegetable oils. J. Appl. Polym. Sci. 2000, 75, 1441-1446. [CrossRef]

11. Gobin, M.; Loulergue, P.; Audic, J.-L.; Lemiègre, L. Synthesis and characterisation of bio-based polyester materials from vegetable oil and short to long chain dicarboxylic acids. Ind. Crops Prod. 2015, 70, 213-220. [CrossRef]

12. Caillol, S.; Desroches, M.; Boutevin, G.; Loubat, C.; Auvergne, R.; Boutevin, B. Synthesis of new polyester polyols from epoxidized vegetable oils and biobased acids. Eur. J. Lipid Sci. Technol. 2012, 114, 1447-1459. [CrossRef]

13. Desroches, M.; Escouvois, M.; Auvergne, R.; Cailol, S.; Boutevin, B. From Vegetable Oils to Polyurethanes: Synthetic Routes to Polyols and Main Industrial Products. Polym. Rev. 2012, 52, 38. [CrossRef]

14. Xia, Y.; Henna, P.H.; Larock, R.C. Novel thermosets from the cationic copolymerization of modified linseed oils and dicyclopentadiene. Macromol. Mater. Eng. 2009, 294, 590-598. [CrossRef]

15. Biermann, U.; Metzger, J.O.; Meier, M.A.R. Acyclic triene metathesis oligo- and polymerization of high oleic sun flower oil. Macromol. Chem. Phys. 2010, 211, 854-862. [CrossRef]

16. Akintayo, C.O.; Mutlu, H.; Kempf, M.; Wilhelm, M.; Meier, M.A.R. Acyclic triene metathesis polymerization of plukenetia conophora oil: Branched polymers by direct polymerization of renewable resources. Macromol. Chem. Phys. 2012, 213, 87-96. [CrossRef] 
17. Kreye, O.; Tóth, T.; Meier, M.A. Copolymers derived from rapeseed derivatives via ADMET and thiol-ene addition. Eur. Polym. J. 2011, 47, 1804-1816. [CrossRef]

18. Lligadas, G. Renewable polyols for polyurethane synthesis via thiol-ene/yne couplings of plant oils. Macromol. Chem. Phys. 2013, 214, 415-422. [CrossRef]

19. Ronda, J.C.; Lligadas, G.; Galià, M.; Cádiz, V. Vegetable oils as platform chemicals for polymer synthesis. Eur. J. Lipid Sci. Technol. 2011, 113, 46-58. [CrossRef]

20. Karmakar, G.; Ghosh, P. Atom Transfer Radical Polymerization of Soybean Oil and Its Evaluation as a Biodegradable Multifunctional Additive in the Formulation of Eco-Friendly Lubricant. ACS Sustain. Chem. Eng. 2016, 4, 775-781. [CrossRef]

21. Vilela, C.; Cruciani, L.; Silvestre, A.J.D.; Gandini, A. Reversible polymerization of novel monomers bearing furan and plant oil moieties: A double click exploitation of renewable resources. RSC Adv. 2012, 2, 2966. [CrossRef]

22. Gandini, A.; Lacerda, T.M.; Carvalho, A.J.F.; Trovatti, E.; Isikgor, F.H. Remzi Becer Progress of Polymers from Renewable Resources: Furans, Vegetable Oils, and Polysaccharides. Polym. Chem. 2015, 6, 4497-4559.

23. Lacerda, T.M.; Carvalho, A.J.F.; Gandini, A. Two alternative approaches to the Diels-Alder polymerization of tung oil. RSC Adv. 2014, 4, 26829-26837. [CrossRef]

24. Iqbal, M.; Knigge, R.; Heeres, H.; Broekhuis, A.; Picchioni, F. Diels-Alder-Crosslinked Polymers Derived from Jatropha Oil. Polymers 2018, 10, 1177. [CrossRef] [PubMed]

25. Murphy, E.B.; Wudl, F. The world of smart healable materials. Prog. Polym. Sci. 2010, 35, 223-251. [CrossRef]

26. Carruthers, W. (Ed.) 1-The Diels-Alder Reaction-General Aspects. In Cycloaddition Reactions in Organic Synthesis; Tetrahedron Organic Chemistry Series; Elsevier: Oxford, UK, 1990; Volume 8, pp. 1-90.

27. Sastry, G.S.; Murthy, B.G.; Aggarwal, J. Diels-Alder adducts from safflower oil fatty acids: I. Maleic Anhydrine as Dienophile. J. Am. Oil Chem. Soc. 1971, 48, 686-688. [CrossRef]

28. Balakrishna, R.S.; Murthy, B.G.K.; Aggarwal, J.S. Diels-Alder adducts from safflower oil fatty acids: II. Styrene as Dienophile. J. Am. Oil Chem. Soc. 1971, 48, 689-692. [CrossRef]

29. Sastry, G.S.R.; Murthy, B.G.K.; Aggarwal, J.S. Diels-alder adducts from safflower fatty acids: III. Acrylic and related acid dienophiles. J. Am. Oil Chem. Soc. 1972, 49, 192-195. [CrossRef]

30. Biermann, U.; Butte, W.; Eren, T.; Haase, D.; Metzger, J.O. Regio- and stereoselective Diels-Alder additions of maleic anhydride to conjugated triene fatty acid methyl esters. Eur. J. Org. Chem. 2007, 23, 3859-3862. [CrossRef]

31. Shibata, M.; Teramoto, N.; Nakamura, Y. High Performance Bio-Based Thermosetting Resins Composed of Tung Oil and Bismaleimide. J. Appl. Polym. Sci. 2011, 119, 896-901. [CrossRef]

32. Vilela, C.; Cruciani, L.; Silvestre, A.J.D.; Gandini, A. A double click strategy applied to the reversible polymerization of furan/vegetable oil monomers. Macromol. Rapid Commun. 2011, 32, 1319-1323. [CrossRef]

33. Frias, C.F.; Fonseca, A.C.; Coelho, J.F.J.; Serra, A.C. Straightforward functionalization of acrylated soybean oil by Michael-addition and Diels-Alder reactions. Ind. Crops Prod. 2015, 64, 33-38. [CrossRef]

34. Gandini, A.; Lacerda, T.M.; Carvalho, A.J.F. A straightforward double coupling of furan moieties onto epoxidized triglycerides: Synthesis of monomers based on two renewable resources. Green Chem. 2013, 15, 1514. [CrossRef]

35. Yuliati, F.; Deuss, P.J.; Heeres, H.J.; Picchioni, F. Towards thermally reversible networks based on furan-functionalization of jatropha oil. Molecules 2020, in press.

36. Kossmehl, G.; Nagel, H.-I.; Pahl, A. Cross-linking reactions on polyamides by bis- and tris(maleimide)s. Angew. Makromol. Chem. 1995, 227, 139-157. [CrossRef]

37. Polgar, L.M.; Cerpentier, R.R.J.; Vermeij, G.H.; Picchioni, F.; Van Duin, M. Influence of the chemical structure of cross-linking agents on properties of thermally reversible networks. Pure Appl. Chem. 2016, 88, 1103-1116. [CrossRef]

38. Toncelli, C.; De Reus, D.C.; Picchioni, F.; Broekhuis, A.A. Properties of reversible Diels-Alder furan/maleimide polymer networks as function of crosslink density. Macromol. Chem. Phys. 2012, 213, 157-165. [CrossRef]

39. ASTM. Standard Test Method for Peel Resistance of Adhesives (T-Peel Test); ASTM International: West Conshohocken, PA, USA, 2008. 
40. Iqbal, M. Synthesis and Properties of Bio-Based and Renewable Polymeric Products. Ph.D. Thesis, University of Groningen, Groningen, The Netherlands, 2014.

41. Fan, M.; Liu, J.; Li, X.; Zhang, J.; Cheng, J. Recyclable Diels-Alder furan/maleimide polymer networks with shape memory effect. Ind. Eng. Chem. Res. 2014, 53, 16156-16163. [CrossRef]

42. Teramoto, N.; Niwa, M.; Shibata, M.; Teramoto, N.; Niwa, M.; Shibata, M. Synthesis and Properties of Trehalose-Based Flexible Polymers Prepared from Difurfurylidene Trehalose and Maleimide- Terminated Oligo(dimethylsiloxane) by Diels-Alder Reactions. Materials 2010, 3, 369-385. [CrossRef]

43. Brouwer, F. Developing Suitable Polymer Semiconducrors for the Application in BioFETs. Ph.D. Thesis, University of Groningen, Groningen, The Netherlands, 2011.

44. Bandzierz, K.; Reuvekamp, L.; Dryzek, J.; Dierkes, W.; Blume, A.; Bielinski, D. Influence of Network Structure on Glass Transition Temperature of Elastomers. Materials 2016, 9, 607. [CrossRef]

45. Rohman, A.; Riyanto, S.; Sasi, A.M.; Yusof, F.M. The use of FTIR spectroscopy in combination with chemometrics for the authentication of red fruit (Pandanus conoideus Lam) oil from sunflower and palm oils. Food Biosci. 2014, 7, 64-70. [CrossRef]

46. Nisar, J.; Razaq, R.; Farooq, M.; Iqbal, M.; Khan, R.A.; Sayed, M.; Shah, A.; Rahman, I. Enhanced biodiesel production from Jatropha oil using calcined waste animal bones as catalyst. Renew. Energy 2017, 101, 111-119. [CrossRef]

47. Liu, X.; Du, P.; Liu, L.; Zheng, Z.; Wang, X.; Joncheray, T.; Zhang, Y. Kinetic study of Diels-Alder reaction involving in maleimide-furan compounds and linear polyurethane. Polym. Bull. 2013, 70, 2319-2335. [CrossRef]

48. Polgar, L.M. Thermoreversible Cross-Linking of Rubber. Ph.D. Thesis, University ofGroningen, Groningen, The Netherlands, 2017.

49. Froidevaux, V.; Borne, M.; Laborbe, E.; Auvergne, R.; Gandini, A.; Boutevin, B. Study of the Diels-Alder and retro-Diels-Alder reaction between furan derivatives and maleimide for the creation of new materials. RSC Adv. 2015, 5, 37742. [CrossRef]

50. Canadell, J.; Fischer, H.; De With, G.; Van Benthem, R.A.T.M. Stereoisomeric effects in thermo-remendable polymer networks based on Diels-Alder crosslink reactions. J. Polym. Sci. Part A Polym. Chem. 2010, 48, 3456-3467. [CrossRef]

51. Jegat, C.; Mignard, N. Effect of the polymer matrix on the thermal behaviour of a furan-maleimide type adduct in the molten state. Polym. Bull. 2008, 60,799-808. [CrossRef]

52. Bose, R.K.; Kötteritzsch, J.; Garcia, S.J.; Hager, M.D.; Schubert, U.S.; Van der Zwaag, S. A rheological and spectroscopic study on the kinetics of self-healing in a single-component diels-alder copolymer and its underlying chemical reaction. J. Polym. Sci. Part A Polym. Chem. 2014, 52, 1669-1675. [CrossRef]

53. Sahu, U.S.; Bhadani, S.N. Homopolymerization of maleimide. Die Makromol. Chem. Rapid Commun. 1982, 3, 103-107. [CrossRef]

54. Sigma Aldrich. 1,1'-(Methylenedi-4,1-phenylene)Bismaleimide; Sigma Aldrich: Eichenzell, Germany, 2016.

55. Musto, P.; Martuscelli, E.; Ragosta, G.; Russo, P.; Scarinzi, G. An interpenetrated system based on a tetrafunctional epoxy resin and a thermosetting bismaleimide: Structure-properties correlation. J. Appl. Polym. Sci. 1998, 69, 1029-1042. [CrossRef]

56. Sava, M.; Gaina, C.; Gaina, V.; Chiriac, C.; Stoica, G.H.; Hamciuc, C. Preparation and characterization of bismaleimides containing ether bonds. Des. Monomers Polym. 2012, 1, 135-145. [CrossRef]

57. Royall, P.G.; Huang, C.; Tang, S.J.; Duncan, J.; Van-de-Velde, G.; Brown, M.B. The development of DMA for the detection of amorphous content in pharmaceutical powdered materials. Int. J. Pharm. 2005, 301, 181-191. [CrossRef]

58. Patel, Y.S.; Patel, H.S. Thermoplastic-thermosetting merged polyimides via furan-maleimide Diels-Alder polymerization. Arab. J. Chem. 2017, 10, S1373-S1380. [CrossRef]

59. Curliss, D.B.; Cowans, B.A.; Caruthers, J.M. Cure Reaction Pathways of Bismaleimide Polymers: A Solid-State 15N NMR Investigation. Macromolecules 1998, 31, 6776-6782. [CrossRef]

60. Fischer, G. High Temperature and Toughened Bismaleimide Composite Materials for Aeronautics. Ph.D. Thesis, L'Institut National des Sciences Appliquées de Lyon, Lyon, France, 2015. 
61. Bai, N.; Simon, G.P.; Saito, K. Characterisation of the thermal self-healing of a high crosslink density epoxy thermoset. New J. Chem. 2015, 39, 3497-3506. [CrossRef]

62. Kwakernaak, A.; Hofstede, J.; Poulis, J.; Benedictus, R. Improvements in bonding metals for aerospace and other applications. Weld. Join. Aerosp. Mater. 2012, 235-287. [CrossRef]

(C) 2020 by the authors. Licensee MDPI, Basel, Switzerland. This article is an open access article distributed under the terms and conditions of the Creative Commons Attribution (CC BY) license (http://creativecommons.org/licenses/by/4.0/). 